\title{
Chitosan-based advanced materials for docetaxel and paclitaxel delivery: Recent advances and future directions in cancer theranostics
}

Milad Ashrafizadeh ${ }^{\mathrm{a}}$, Zahra Ahmadi ${ }^{\mathrm{b}}$, Neda Mohamadic ${ }^{\mathrm{c}}$ Ali Zarrabi ${ }^{\mathrm{d}}$, Sara Abasi ${ }^{\mathrm{e}}$, Gholamreza Dehghannoudeh ${ }^{\mathrm{c}}$, Rosette N. Tamaddondoust ${ }^{\mathrm{f}}$, Hashem Khanbabaei ${ }^{\mathrm{g}}$, Reza Mohammadinejad $^{\mathrm{c}^{*}, \text { Vijay Kumar Thakurh,i* }}$

aDepartment of Basic Science, Faculty of Veterinary Medicine, University of Tabriz, Tabriz, Iran

${ }^{b}$ Department of Basic Science, Faculty of Veterinary Medicine, Islamic Azad Branch, Shushtar,

Khuzestan, Iran

'Pharmaceutics Research Center, Institute of Neuropharmacology, Kerman University of Medical Sciences, Kerman, Iran

dSUNUM, Nanotechnology Research, and Application Center, Sabanci University, Istanbul, Turkey

${ }^{\mathrm{e} D e p a r t m e n t}$ of Biomedical Engineering, Texas A\&M University, College Station, TX 77843, US A

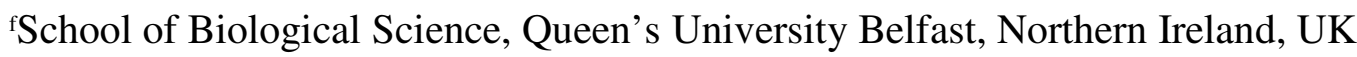

gMedical Physics Department, School of Medicine, Ahvaz Jundishapur University of Medical Sciences, Ahvaz, Iran

${ }^{h}$ Enhanced Composites and Structures Center, School of Aerospace, Transport and Manufacturing, Cranfield University, Bedfordshire MK43 0AL, UK

iDepartment of Mechanical Engineering, School of Engineering, Shiv Nadar University, Uttar Pradesh, 201314, India

*Co-corresponding Authors:

Reza Mohammadinejad, E-mail: r.mohammadinejad87@gmail.com

Vijay Kumar Thakur, E-mail: Vijay.Kumar@cranfield.ac.uk 


\begin{abstract}
Paclitaxel (PTX) and docetaxel (DTX) are key members of taxenes with high anti-tumor activity against various cancer cells. These chemotherapeutic agents suffer from a number of drawbacks and it seems that low solubility in water is the most important one. Although much effort has been made in improving the bioavailability of PTX and DTX, the low bioavailability and minimal accumulation at tumor sites are still the challenges faced in PTX and DTX therapy. As a consequence, biomaterial-synthesized NPs have attracted much attention due to unique properties. Among them, chitosan (CS) is of interest due to its great biocompatibility. CS is a positively charged polysaccharide with the capability of interaction with negatively charged biomolecules. Besides, it can be processed into the sheet, micro/nano-particles, scaffold, and is dissolvable in mildly acidic $\mathrm{pH}$ similar to the $\mathrm{pH}$ of the tumor microenvironment. Keeping in mind the different applications of CS in the preparation of nanocarriers for delivery of PTX and DTX, in the present review, we demonstrate that how CS functionalized-nanocarriers and CS modification can be beneficial in enhancing the bioavailability of PTX and DTX, targeted delivery at tumor site, image-guided delivery and co-delivery with other anti-tumor drugs or genes.
\end{abstract}

Keywords: Chitosan, Chemotherapy, Nanoparticles, Paclitaxel, Docetaxel, Delivery 


\section{Abbreviations:}

CS, chitosan;

PTX, paclitaxel;

DTX, docetaxel;

FDA, Food and Drug Administration;

NPs, nanoparticles;

CRC, colorectal cancer;

PLGA, poly-(lactic-co-glycolic acid);

PLL, polycaprolactone;

EE, entrapment efficiency;

ss-pLG, star shaped poly (d,1-lactide)-b-gelatin;

PLA, poly (lactic acid);

CHN, CS hollow NPs;

NOSC, N-octyl-O-sulfate CS;

P-gp, P-glycoprotein;

PTX-M, PTX-coated CS micelles;

GNR, gold nanorods;

CPNPs, CS-coated polymer NPs;

OCBCS, N-octyl-N-(2-carboxylbenzoyl) CS;

MC, mesoporous carbon nanomatrix; 
CCS, carboxymethyl CS;

DTX-C-G/P, DTX-loaded thermos-responsive CS/b-glycerophosphate hydrogel;

GSH, glutathione;

FA, folic acid;

DA, deoxycholic acid;

OCMC, o-carboxymethylated CS;

FACC, FA-cholesterol-CS;

$\mathrm{TF}$, transferrin;

TFRs, TF receptors;

HA, hyaluronic acid;

EGFR, epidermal growth factor receptor;

BI, biotinylated;

NC, nanocochleates;

PSMA, prostate-specific membrane antigen;

$\mathrm{GC}$, gastric cancer;

miR, microRNA;

siRNA, short interfering RNA;

LNA, locked nucleic acid;

pDNA, plasmid DNA;

DOX, doxorubicin; 
Alg, alginate;

ACHC, Alg coated CS hollow nanosphere;

CNT, carbon nanotube;

$\mathrm{BB}$, berbamine;

LDL, low density lipoprotein;

NSC, N-succinyl CS;

LA, lipoid acid;

IGF-1R, insulin-like growth factor receptor-1;

MUC1, mucin-1;

CS-AuNPs, CS-stabilized gold NPs;

PAI, photoacoustic imaging;

DMC, 3,6-O,O'-dimyristoyl CS;

SLNs, solid lipid NPs;

CDs, cyclodextrins. 


\section{Introduction}

Driven from the second most abundant polysaccharide, chitin, chitosan (CS) is a lowcost biomaterial which its favorable characteristics have turned in into one of the most explored biomaterials. CS-based materials have been used in the versatile area including biological medicine [1-3]. The first mention of the inveterate extraction of chitin backed to 1799 by Hatchett, but its discovery attributed to Braconnot, twelve years later, who extracted it from fungi [4]. Chitin has been extracted mostly from crustaceans and fungi, but its extraction from insects and vertebrates are also reported [5]. The research by Rouget in 1859 resulted in the discovery of CS, the most important derivative of chitin, which is obtained by the deacetylation of chitin, removing the acetamido groups leaving the free amino groups. CS is regarded as a random co-polymer of $\gamma$-glucosamine and $\mathrm{N}$-acetyl$\gamma$-glucosamine units linked with $\beta(1,4)$ - glycosidic bonds, providing the polymer with two functional groups, hydroxyl, and amine, and overall positive charge. It is dissolvable in mild acidic condition, naturally gellable with $\mathrm{pH}$, can be processed into sheet, micro/nanoparticles, scaffold, can be chemically modified via its functional groups, can interact with negatively charged biomolecules and cell surface because of its positive charge [6,7], enzymatically degradable [8], generally non-cytotoxic, biocompatible and having antibacterial effects. Owing to its bio-friendly characteristics, CS-based materials have been applied in multiple fields of medicine including replacement/ supplemental to tissue (dental, bone and cartilage, wound healing, regenerative medicine) [9-11], as carrier and delivery vehicle for biomolecule cargo (targeted drug delivery, stimuli-response release) [12, 13], cell encapsulation/ cell delivery [14], and 3D bioprinting [15]. As drug carriers, CS-based materials have been developed as micro/nano-particles based on crosslinking the CS in the presence of cargo. This process can be approached via developing surfactant-stabled CS droplets in water/oil emulsion followed by crosslinking CS, coacervation of aqueous acidic CS solution in alkaline, spray-drying of CS solution, ionotropic gelation of CS in a bath of polyanion solution, and reverse micellar methods [16, 17]. Crosslinking could be performed either covalently, e.g. using glutaraldehyde [18], or physically, e.g. using polyanions [19]. The size and size distribution of NPs being controlled by the concentration and molecular weight of reactants, stirring speed, duration of process, $\mathrm{pH}$ and temperature of solutions [20, 21].

\section{Paclitaxel and docetaxel}


Finding an effective way to cure cancer, the leading cause of death on a worldwide scale, is still a challenge [22]. The rate of cancer incidence is significantly increased for the past few years, probably due to the exposure to potentially toxic agents [23-26]. However, nanotechnology techniques and methods can help to increase the efficiency of the drug delivery and releasing control in the tumor sites [27]. The conventional chemotherapeutic agents such as paclitaxel (PTX) (PubChem CID: 36314) [28] and docetaxel (DTX) (PubChem CID: 148124) [29] have been loaded on nanostructures to improve their potential in chemotherapy [30, 31]. PTX with chemical formula of C47H51O41 (figure 1) [32] is one of the most common therapeutic compounds extensively applied for treatment of a number of cancers such as lung cancer [33], ovarian cancer [34], brain tumors [35], cervical cancer [36], breast cancer [37] and colorectal cancer [38]. The discovery of PTX returns to 1963 when it was isolated from the bark of the pacific yew Taxus brevifolia [39]. in 1992, the Food and Drug Administration (FDA) confirmed the application of PTX for cancer therapy [40]. As a semisynthetic plant alkaloid, PTX belongs to the category of Taxanes s that restabilize the microtubule cytoskeleton against depolymerization (figure 2) [41]. As one of the key members of the cytoskeleton, microtubules play a remarkable role in a variety of biological processes including preservation of cell shape, molecular signaling pathways, contributing in the transportation of cell organelles and more import the antly, generation of the mitotic spindle for ensuring the progression of the cell cycle [42-45]. PTX impacts the cell division via promoting the polymerization of the tubulin proteins and production of non-functional microtubules [46]. DTX, another member of taxanes, is extensively used for cancer treatment as well (figure 1) [47-51]. This chemotherapeutic compound was first introduced in 1990 from the European yew tree, Taxus baccata [52]. Similar to PTX, DTX also stabilizes the microtubules and disrupts the microtubule dynamics which leads to mitosis prevention and cell proliferation [53]. FDA approved the application of DTX for the treatment of cancer in 1996 [54]. Despite its potential of anti-tumor activities, DTX is a lipophilic agent with low solubility in water which restricts its efficiency $[47,55,56]$. The current formulation of the DTX contains ethanol has an adverse impact on its bioavailability [47, 55, 56]. In this context, nano-techniques can be a promising approach to improve the bioavailability of DTX with no side effects on healthy cells or tissues. In spite of the efficient benefits of phytoconstituents, they show some of the challenges such as limited knowledge of pharmacokinetic profiles and the requirement of high doses that are usually associated with toxicity $[57,58]$. Over recent years, the use of new drug delivery systems such as encapsulation of herbal ingredients with nanoparticles would likely affect the stability and 
pharmacokinetics of the carried compounds [59]. In the case of PTX and DTX, there are some challenges such as low water solubility $(0.3 \mu \mathrm{g} / \mathrm{mL})$, presystemic metabolism, high protein binding, high affinity to P-glycoprotein (P-gp), and some adverse effects which lead to their low bioavailability $[60,61]$. In this study, a broad range of biocompatible, biodegradable, and nontoxic polymeric nanoparticles, micelles, and nanotubes were introduced to improve the pharmacokinetic profiles of DTX and PTX to increase the solubility, bioavailability, and intracellular accumulation to tumors cells.

\section{Chitosan nanocarriers}

\subsection{Chitosan nanoparticles for PTX delivery}

Glioblastoma is a malignant brain tumor with high prevalence and surgery is considered as the best option in glioblastoma therapy [62]. However, patients with glioblastoma have a low survival time ( $<2$ years). The possibility of recurrence is at the highest rate in glioblastoma and anti-tumor drugs should effectively eliminate cancer cells. In order to provide efficient anti-glioblastoma therapy, targeted delivery of chemotherapeutic agents such as PTX is of interest. PTX-loaded CS NPs have demonstrated great potential in the treatment of glioblastoma by providing a prolonged release of the drug, improving drug bioavailability, enhancing hemocompatibility and more importantly, exerting more cytotoxic effect compared to the PTX alone [63]. Higher cellular uptakes/efficacy of the nanoformulation of PTX elucidated that 1,3ß-Glucan shell of the core NPs actively targeted various overexpressed receptors on both glioma stem cell lines (C6) and glioma cancer cell line (LN-18). Due to the dose-dependent toxicities of PTX [64], nanocarriers can provide a platform for enhancing the anti-tumor activity of PTX and simultaneously, reducing its toxicity by loading a low amount of drug on NPs [65]. Making an increase in the EE\% and loading efficiency of PTX in NPs are obtained via developing novel strategies in the synthesis of NPs. It appears that the emulsification-crosslinking method in a W/O emulsion system can be considered as a smart strategy in preparation of CS NPs [66], as the resulting NPs demonstrated excellent loading efficiency (8.55\%) and EE\% (94.01\%) with high biocompatibility.

Jiang et al. have examined the efficacy of CS hollow NPs (CHN) for the delivery of PTX in lung cancer [67]. The limited space of a nanometer-scale hollow structure was used in 
order to enhance the water solubility, preventing drug crystallinity, and diminishing the particle size. Notably, the resulting CHN had a diameter size of about $200 \mathrm{~nm}$ that was lower compared to the previously reported particle sizes. The high biodegradability of CHN led to the release of PTX after their uptake by A549 cells, resulting in apoptotic cell death and consequently, reduced viability and malignancy of cancer cells. While PTX has been applied for the treatment of a variety of cancer, its dose-dependent toxicity is still a challenge which could be addressed using nanocarriers as they can enhance the targeted delivery of PTX to the tumor site by delivering a low amount of the PTX hence reduces the toxicity side effects in healthy neighbor cells. To date, the prepared CS NPs for delivery of PTX have demonstrated excellent properties in terms of biocompatibility, targeted delivery, biodegradability at the tumor site and cellular uptake. Besides, PTX-loaded CS NPs have dramatically diminished the viability, proliferation, and migration of cancer cells by induction of apoptotic cell death [68-79].

\subsection{Chitosan nanoparticles for DTX delivery}

Breast cancer with high malignancy and recurrence, which are two important features of this condition, is one of the most life-threatening threatening illnesses in women [80-83]. CS NPs can improve the chemotherapeutic efficiency of DTX due to its excellent drug entrapment (6576\%) and sustained-release behavior of CS which significantly inhibits the viability and proliferation of MDA-MB-231 breast cancer cells [84]. Moreover, breast cancer cells treated with encapsulated DTX in CS NPs showed a higher ratio of Bax (an apoptotic factor) over the BCL-2 (a down regulator of anti-apoptotic) compared to the cells treated with noncapsulated DTX [85].

Colorectal cancer (CRC), is another lead life-threatening illness in Europe and Asia [86, 87]Therefore, improving the efficacy of chemotherapy is of importance in improving the survival time of patients with CRC. Badran et al have investigated the anti-tumor activity of DTX CS-coated poly (lactic-co-glycolic acid) (PLGA)/polycaprolactone (PCL) NPs [88]. These nanocarriers have demonstrated significant drug entrapment efficiency (EE\%) (PCL NPs: $67.1 \%$ and PLGA NPs: 76.2\%), increasing the cytotoxicity potential of DTX, as well as the decreasingthe cell growth up to 50\%. Moreover, PLGA/PCL NPs can increase the bioavailability of the DTX by about 4 times higher. One of the most challenging problems in the delivery of chemotherapeutic agents in the low biocompatibility of 
synthesized NPs which was addressed by Balavigneswaran et al. through conjugation of starshaped poly (d, 1-lactide)-b-gelatin (ss-pLG) into biodegradable poly (lactic acid) (PLA). On the other hand, the ss-pLG scaffold provides the burst release of DTX [89]. CS NPs demonstrate high EE\% and prolonged-release behavior, and simultaneously, improve the intestinal permeation of DTX [90].

\section{Chitosan micelles for PTX delivery}

It has been shown that micelles are potential candidates in enhancing the bioavailability of drugs with low aqueous solubility [91, 92]. As core-shell NPs spontaneously generated in water from amphiphilic molecules, micellar NPs are able to protect drugs from degradation [93, 94]. These excellent properties have led to the extensive application of micelles for delivery of PTX, an anti-tumor compound with low water solubility. CS micellar NPs are capable of releasing PTX in prolonged-release behavior [95]. PTX-loaded CS micelles remarkably enhance the anti-cancer effect of PTX without influencing its cytotoxicity and simultaneously, improve the distribution of PTX in tissues including liver, spleen, lung, and kidney [96]. However, it has been reported that the levels of CS micellar NPs are higher in the liver and spleen compared to the heart and kidney [97].

The resistance of cancer cells to chemotherapy is still a challenge. Recently, Jin et al have investigated the potential of PTX-loaded N-octyl-O-sulfate CS (NOSC) micelles for decreasing the viability and proliferation of resistant tumor cells [98]. It was found that PTX-loaded NOSC micelles: 1) increase the accumulation of PTX at the tumor site, and 2) enhance the residence time of PTX. High accumulation of PTX at the tumor site is a result of using NOSC, so that NOSC exerts an inhibitory impact on the P-glycoprotein (P-gp) by induction of P-gp ATPase to suppress the binding of PTX with P-gp, leading to the entering of PTX into cancer cells and simultaneously, decrease the fluidity of cell membrane. P-gp is involved in the inhibition of entering of chemotherapeutic agents into cells [99] and P-gp inhibition by NOSC facilitates the entering of PTX into tumor cells. Moreover, an increase in the incidence time of PTX by NOSC micellar NPs is due to the efficacy of these nanocarriers in intracellular delivery, drug loading, tumor targetability and increasing the stability of the drug. These excellent properties have led to the enhanced cytotoxicity of PTX-loaded NOSC micellar NPs against resistant hepatocellular carcinoma cells. In order to promote the targetability of NOSC NPs, a polyethylene glycol (mPEG) group can be added. Besides, the mPEG group 
leads to a decrease in the removal of CS micellar NPs by the reticuloendothelial system (RES) [100]. These studies highlight this fact that PTX has a low bioavailability which restricts its anti-tumor activity and enhancing the dose of PTX is associated with increased toxicity of PTX. Moreover, using a high amount of a chemotherapeutic agent such as PTX elevates the chance of resistance of cancer cells that consequently, decreases the efficacy of chemotherapy. It seems that CS micellar NPs are potential candidates to improve the bioavailability and anti-tumor potential of PTX. Besides, CS micelles are capable of diminishing the toxicity of PTX by loading a low amount of PTX on NPs. In contrast to CS NPs, CS micelles have been designed based on targeting tumor receptors such as P-gp or integrin receptors to promote the entering of PTX into cancer cells [101-110]. However, more studies are required to develop CS micelles targeting surface receptors and this capability should be considered for CS NPs.

\section{Chitosan microstructures for PTX and DTX delivery}

Various therapeutic agents with different sizes can be loaded on microspheres to improve their bioavailability [111-113]. A variety of strategies are applied in order to administer therapeuticloaded microspheres. However, microspheres are mainly delivered through subcutaneous and intramuscular routes [114-116]. Microspheres are particles with the size at the range of 5$15 \square \mathrm{m}$ and the development of microsphere induced a dramatic evolution in enhancing the bioavailability of anti-tumor drugs by providing a prolonged-release behavior [117]. Moreover, decreasing adverse impacts and providing targeted delivery are among the other beneficial effects of using microspheres for drug delivery [118]. Wang and colleagues have investigated the potential of DTX-loaded CS microspheres for the delivery of the drug to the lungs [119]. A water-in-oil emulsification method was used to synthesize glutaraldehyde crosslinked microspheres. The resulting microspheres demonstrated excellent properties such as spherical shape, smooth surface, high EE\% (88.1\%) and drug loading (18.7\%). These carriers had excellent biocompatibility with the capability of releasing a drug in a sustained-release behavior. In the case of PTX, the efficacy of CS-modified PLGA NPs with the capability of transient formation of microaggregates has been evaluated for lung delivery [120]. The modification of NPs by CS led to remarkable alterations in the properties of PLGA NPs so that after contacting plasma, the particle size of NPs enhanced from 200-300 nm to $2670 \mathrm{~nm}$. However, this increase was reversed after $5 \mathrm{~min}$ and the mean particle size of CS-modified PLGA NPs returned to $350.7 \mathrm{~nm}$. 
Besides, CS modification provided a positive zeta potential, high cellular uptake and enhanced cytotoxicity against lung cancer cells (A549 cells). The in vivo experiment manifested a significant change in the CS-modified PLGA NPs so that upon the administration of NPs through the tail vein, an increase in trapping in lung capillaries and uptake by endothelial cells occurred due to the formation of microaggregates in the bloodstream. To date, two studies have examined the potential of CS-modified microspheres for delivery of PTX and DTX, demonstrating that there is still a long way for further investigations [119]. The incredible role of CS modification is undeniable, so that conjugation of CS is associated with high cellular uptake and cytotoxicity against cancer cells.

\section{Chitosan hydrogels for PTX delivery}

A three-dimensional network generated from hydrophilic agents is defined as hydrogels [121, 122]. The aim of the production of hydrogels is to form insoluble polymer matrices. These water-swollen networks are capable of loading a high concentration of water without being dissolved in water. Hydrogels have a number of benefits such as adjustable stiffness and excellent biocompatibility, leading to their tremendous applications in biomedicine [123125]. Notably, CS-modified hydrogels have demonstrated great potential in releasing drugs in a prolonged-release behavior, resulting in their usefulness for the delivery of chemotherapeutic agents such as PTX in cancer therapy [126, 127]. An essential advantage of hydrogels is providing a nanocomposite to load other therapeutics. This strategy diminishes the need for the anti-tumor drug, and by reducing the concentration of the medicine, the chance of resistance decreases, while the inhibitory effect on the growth and viability of cancer cells is high. In line with this strategy, Zhang and colleagues designed nanocomposite hydrogel for loading gold nanorods (GNR) and PTX-loaded CS micelles (PTX-M) in photothermal-chemotherapy [128]. The synthesized thermo-sensitive hydrogel matrix effectively delivered GNR and PTX-M at the tumor site. Exposing to laser ablation produced GNR-mediated photothermal damage. However, some tumor cells may rescue from photothermal therapy. In order to maximize the anti-tumor treatment, the PTX-M was loaded on nanocomposite hydrogel. These nanocarriers released PTX in a sustained-release behavior, resulting in the elimination of cancer cells evaded from photothermal ablation. 


\section{Stimuli-responsive chitosan nanoparticles for PTX and DTX delivery}

\section{1. pH-responsive chitosan nanoparticles}

Stimuli-responsive NPs have opened a new perspective in cancer therapy. This is due to the alteration of $\mathrm{pH}$ in the tumor microenvironment. CS-functionalized NPs coated with polymers are able to release PTX in a prolonged-release behavior (figure 3) [129]. These CS-coated polymer NPs (CPNPs) have a PLGA core, to load and retain drugs, covered by a polydopamine. In order to functionalize NPs, CS modification was performed through the polydopamine layer to functionalize NPs. CPNPs released PTX in a sustained release behavior so that $80 \%$ of PTX was released during $48 \mathrm{~h}$. Because of the mild acidic nature of CS (PKa of 6.5), the CPNPs are in non-ionized form at mild acidic pHs (of around 6.5) hence relatively soluble and diffusive through the lipidic membrane of cells. Due to this fact, CPNPs demonstrated higher delivery of drugs at a mildly acidic $\mathrm{pH}$ of the tumor microenvironment $(\mathrm{pH}=6)$ compared to the slightly basic extracellular environment of normal tissues $(\mathrm{pH}=7.4)$ [130]. There is a difference in the $\mathrm{pH}$ of the tumor microenvironment $(\mathrm{pH}=6.3-6.8)$ and endosomes or lysosomes $(\mathrm{pH}=5)$ [131]. It seems that $\mathrm{pH}$-responsive NPs start releasing the drug after entering to the tumor microenvironment. So, it is necessary to release the drug in a sustained release behavior to ensure the delivery of the drug into cancer cells. N-octyl-N-(2-carboxylbenzoyl) CS (OCBCS) can produce micellar NPs with the capability of encapsulating PTX and delivering at a prolonged release behavior [132]. The pH-responsive NPs play a more important role during oral administration of anti-tumor drugs. These NPs should be able to effectively release a drug in the intestine while protecting the drug from degradation in the stomach. Carboxymethyl CS/phospholipid bilayer-capped mesoporous carbon NPs are useful nanocarriers in the delivery of anti-tumor drugs such as DTX [133]. These nanocarriers are composed of three individual parts: A) a mesoporous carbon nano matrix [131] for drug loading; B) a positively charged phospholipid (PL) layer providing the sustained release of a drug and C) a negatively charged carboxymethyl CS (CCS) provides pH-responsive drug release. $\mathrm{pH}=1.2$ and $\mathrm{pH}=6.8$ were selected to mimic the $\mathrm{pH}$ of gastric and intestinal fluids, respectively. Up to $80 \%$ of DTX release occurred in $\mathrm{pH}=6.8$, demonstrating the potential of these nanocarriers for oral delivery. The slight decline in the $\mathrm{pH}$ of the tumor extracellular environment (6.5) and its similarity to the pKa of CS made CS-based materials suitable for 
drug carriers in chemotherapy for targeted delivery into cancerous tissues. The carrier can be engineered to release the drug when exposed to the $\mathrm{pH}$ gradient of the tumor not normal tissue.

\subsection{Thermo-responsive chitosan nanoparticles}

Thermo-responsive nanocarriers are another great option for the delivery of PTX and DTX. One of the difficulties in PTX therapy is the formation of PTX crystals associated with decreased anti-tumor potential of PTX. The application of PLGA microparticles and CS thermo-responsive gels is beneficial in the inhibition of PTX crystallization [134]. It has been demonstrated that in order to provide high anti-tumor activity, the lowest concentration of PTX should be used [135]. A combination of CS gel and PLGA microparticles allows the application of a low amount of PTX with high anti-tumor activity against mammary adenocarcinoma cells. More importantly, the in vivo experiment on tumor-bearing mice revealed that CS NPs have anti-tumor activity and loading PTX significantly diminishes the tumor growth and volume. In contrast, Li and colleagues prepared DTX-loaded thermo-responsive CS/b-glycerophosphate hydrogel (DTX-C-/P) [136]. The results of this study demonstrated that $\mathrm{C}-\mathrm{G} / \mathrm{P}$ has no anti-tumor effect (H22 tumor bearing-mice). This discrepancy is needed to be considered in subsequent studies. The second issue is the biodistribution of DTX-C-G/P so that these hydrogels are distributed in the heart, spleen, liver, lung, and kidney. Hence, a low amount of chemotherapeutic agent should be used to minimize adverse impacts. Besides, the resulting nanocarriers need to have great biocompatibility. It appears that the absorption of thermal-sensitive nanocarriers occurs by electrostatic-mediated endocytosis [137]. The high absorption and sustained-release behavior result in the great anti-tumor activity of thermo-responsive nanocarriers [138].

\subsection{Redox-responsive chitosan nanoparticles}

Another intracellular signaling is oxidative stress and there have been attempts to design nanocarriers with the capability of releasing a drug in response to oxidation [139]. Among these nanocarriers, micellar NPs are of interest due to the redox-triggered release of drugs [140, 141]. Notably, this redox-mediated release depends on disulfide bonds found in the matrix crosslink or in auxiliary chains. A high oxidative environment leads to the stabilization of bonds, while the degradation of these bonds occurs in an environment containing antioxidant agents such as glutathione (GSH). The redox-responsive CS micelles have high properties in terms of intracellular release of PTX and high cytotoxicity against tumor 
cells [142]. An important point is an increase in average particle size after exposing to GSH so that it seems that in the highly reducing environment, the micellar structure is hardly found [143]. However, the tumor microenvironment has a partial impact on the size distribution of CS micelles. A high concentration of GSH stimulates the release of PTX from redox-responsive micelles. These nanocarriers demonstrated anti-tumor activity in a time-dependent manner due to accumulation in the cytoplasm.

\section{Chitosan nanocarriers for targeted delivery}

\subsection{Chitosan nanoparticles for targeted PTX delivery}

The enhanced incidence rate of cancer has forced to develop novel methods in cancer therapy. Targeted drug delivery is a smart strategy in combating cancer cells. The identification of receptors on the surface of cancer cells is of importance in the following targeting by nanocarriers. Folate receptors undergo upregulation in tumor cells, while their expression is low in normal cells [144]. There have been efforts to promote the potential of nanocarriers by targeting folate receptors [145]. It appears that CS-folic acid (FA)-deoxycholic acid (DA) micelles are able to mediate the receptor-targeted delivery of PTX (figure 4) [146]. Exposing breast cancer cells (MCF-7) into CS-FA-DA micelles led to a significant decrease in their viability due to increased internalization of micelles through folate receptor-mediated endocytosis. One of the challenges in preparation of CS micelles is the high molecular weight of CS that leads to its poor solubility and consequently, diminishes the biomedical application. The application of water-soluble CS resolves this pitfall due to its low molecular weight [107]. For instance, o-carboxymethylated CS (OCMC) is an amphiphilic derivative of CS with the capability to be used in the synthesis of micelles [147]. The same strategy has been made by Cheng and colleagues [148]. They prepared FA-cholesterol-CS (FACC) micelles for delivery of PTX in the treatment of cervix cancer. The importance of this study was the $\mathrm{pH}$-triggered release of PTX at the mildly acidic $\mathrm{pH}$ of the tumor microenvironment. Taking everything into account, using CS nanocarriers with the capability of targeting folate receptors is beneficial in terms of improving the delivery of PTX into cancer cells. This delivery is induced by folate receptor-mediated endocytosis [149-151]. Another important surface receptor is transferrin (TF). TF receptors (TFRs) stimulate iron absorption via endocytosis and exocytosis [152]. The upregulation of TFRs manifests the high cellular growth [153], and a variety of nanocarriers have been designed to target these surface receptors. TF/PEG/OCMC/fatty acid/PTX (TPOCFP) micelles have been developed for targeting TFRs [154]. TPOCFP micelles 
remarkably enter the nucleus by binding into surface receptors. The high cellular uptake and prolonged-release behavior lead to the high cytotoxicity of TF-functionalized NPs against cancer cells [155]. Attachment of glycol chain into CS produces NPs with high cellular uptake through clathrin-mediated endocytosis, caveola and macropinocytosis that is in favor of delivery of chemotherapeutic agents like PTX and enhancing anti-tumor activity [156]. In order to improve the delivery efficiency of glycol-CS NPs and generate composite NPs, anionic heparin can be used to interact with positively charged glycol CS, leading to the high antitumor activity and targeted drug delivery [157]. Another major importance of heparin modification is cytotoxicity concern. Polycation NPs suffer from a number of drawbacks and it seems that low biocompatibility is the most important one. Neutralizing this positive charge can resolve this difficulty and heparin modification (negative charge) is the best option. Although other negatively charged agents can be applied in neutralizing the positive charge, the interest into heparin emanates from this fact that heparin modification provides the targeted delivery of NPs by tumor cells overexpressed heparanase [158].

Hyaluronic acid (HA) receptors, known as CD44, are exclusively overexpressed on cancer cells [159]. As one of the most malignant cancer cells, the incubation of breast cancer cells with CShyaluronan-coated solid lipid NPs led to decreased viability and proliferation of cancer cells. This high anti-tumor activity is a consequence of the great cellular uptake of these nanocarriers by HA receptors. Overall, targeted delivery systems are able to improve the anti-tumor efficacy of PTX exponentially [160].

\subsection{Chitosan nanoparticles for targeted DTX delivery}

The same strategy is used for DTX delivery. Targeted delivery is of importance in lung cancer therapy due to its high malignancy [161]. Epidermal growth factor receptor (EGFR) is responsible for the invasion and metastasis of lung cancer cells. Besides, the upregulation of EGFR occurs in lung cancer and further targeting is of interest in terms of diminishing the viability and proliferation of cancer cells $[162,163]$. The DTX-loaded CS NPs targeting EGFR are capable of significantly reducing the malignancy of lung cancer cells by induction of $\mathrm{G} 2 / \mathrm{M}$ phase arrest and stimulation of apoptosis and necrosis via diminishing the mitochondrial membrane potential [164]. This great anti-tumor activity is a consequence of high cellular uptake of NPs through EGFR. 
In a study, Poudel and colleagues designed novel biotinylated CS-decorated DTXloaded nanocochleates (BI-CHI-DTX-NCs) for breast cancer therapy [165]. The NCs are a kind of liposomes that phospholipid is affected by divalent cation, leading to the formation of a roll of stacked sheets [166]. NCs have great properties in terms of high biocompatibility, great potential in drug delivery and affordable synthesis $[167,168]$. On the other hand, BI receptors undergo upregulation in various cancers such as breast cancer [169]. So, BI-CHIDTX-NCs should have a combination of the mentioned properties. Surprisingly, NCs demonstrated high efficiency in encapsulating DTX by making hydrogen-binding. Besides, NCs exhibited a pH-dependent release of DTX at mildly acidic $\mathrm{pH}$ $(\mathrm{pH}=5.3)$ similar to the acidic $\mathrm{pH}$ of the tumor microenvironment. BI-CHI-DTX-NCs had high anti-tumor activity against MCF-7 breast cancer cells. Notably, in addition to the potential role of BI in enhancing the cellular uptake of NPs, NC has a remarkable effect itself by providing direct interaction with the cell membrane of cancer cells or phagocytosis [170].

Prostate-specific membrane antigen (PSMA) is a potential target in prostate cancer therapy due to its overexpression and relation with invasion and malignancy [171-174]. Glycol-CS micelles targeted PSMA have high anti-tumor activity due to their great cellular uptake through receptor-mediated endocytosis [175]. Another option in cancer therapy is targeting angiogenesis. It has been demonstrated that angiogenesis is associated with the high proliferation of tumor cells. Drug delivery systems have been designed for the inhibition of angiogenesis [176]. Studies have shown that GX1 can be beneficial in the inhibition of human gastric cancer (GC) angiogenesis $[177,178]$. This inhibitory impact is exerted by specific binding of GX1 to endothelial cells and stimulation of apoptosis $[179,180]$. It seems that DTXloaded CS NPs containing GX1 can be applicable for favorable treatment of GC by both exerting anti-tumor activity and suppressing angiogenesis [181].

One of the challenges faced in the delivery of DTX is the low stability of synthesized CS nanocarriers. In order to overcome this problem, binding a glycol chain into CS is associated with the great stability of CS NPs [182]. Overall, it appears that more attempts have been made in targeted delivery of DTX compared to the PTX with more kinds of receptors. Efforts have been directed into synthesizing CS NPs with great biocompatibility and high cellular uptake [183, 184]. However, the high average particle size of CS NPs is a major problem, resulting in their low efficacy and also high clearance by phagocytosis system. 


\section{Chitosan as co-delivery system}

Using a combination of several of anti-tumor drugs is currently common in cancer therapy. On one hand, this strategy diminishes the chance of resistance of tumor cells. On the other hand, it enhances the anti-tumor potential. In addition to the co-delivery of anti-tumor drugs, gene therapy can be considered as a potential candidate. In respect to the gene mutations in cancer progression, co-delivery of an anti-tumor drug and gene seems beneficial [185, 186]. DNA, RNA, short interfering RNA (siRNA), microRNA (miR), locked nucleic acid (LNA) and plasmid DNA (pDNA) can be loaded on NPs [187]. One of the commonly used combinations in cancer therapy is the application of PTX and doxorubicin (DOX). It is noteworthy to mention that alginate (Alg) coated CS hollow nanosphere (ACHN) is able to remarkably improve the anti-tumor potential of PTX and DOX [188]. ACHN has great biocompatibility so that ACHN a the concentration of $5 \square \mathrm{g} / \mathrm{ml}$ to $500 \square \mathrm{g} / \mathrm{ml}$ is well-tolerated and just diminishes the viability of cells by $20 \%$. Besides, the co-delivery of PTX and DOX by ACHN has higher anti-tumor activity compared to the PTX-DOX. This great antitumor activity is a result of high cellular uptake by cancer cells and synergistic impact of PTX and DOX. Carbon nanotubes (CNTs) have opened a novel perspective in medicine because of their characteristic features. Currently, they are extensively applied in gene delivery, cellular imaging, biosensor, cancer therapy and so on [189, 190]. There have been efforts to use CS functionalized-CNTs for co-delivery of PTX and DOX in order to promote their anti-tumor activity [191]. Notably, both PTX and DOX drugs can be loaded on CNTs. The attachment of DOX is performed by binding to the aromatic surface of the CNTs via it-it stacking, while PTX binds to the benzene ring via it-it stacking. One of the challenges in the functionalization of CNTs is the adverse effects on the stability and biocompatibility [192]. CS functionalization offers no harmful effect on the stability and functionalization of CNTs by providing noncovalent functionalization. At the tumor microenvironment, the release of DOX and PTX occurs due to the protonation of CS that in turn, weakens the attachment of DOX and PTX. It appears that CS functionalized-CNTs have the efficiency of delivery of anti-tumor drugs (figure 5). Plant-derived chemicals are extensively used in chemotherapy due to their great physiological activities [27, 193, 194]. Berbamin (BB) is a naturally occurring nutraceutical compound with high anti-tumor activity. DTX- and BB-loaded CS NPs have demonstrated great capability in the stimulation of apoptotic cell death and down-regulation of survivin. This is due to the higher bioavailability of DTX and BB [195]. The studies suggest that CS functionalization not only improves the 
biocompatibility of NPs but also may provide a pH-triggered release. So, CS can be considered as a potential candidate in the delivery of PTX and DTX [196-198]. Gene delivery can be applied for enhancing the cellular uptake of PTX-loaded CS NPs. Such a strategy can be achieved by co-delivery of MDR1 siRNA and PTX using low density lipoprotein (LDL)coupled N-succinyl CS (NSC) lipoid acid (PTX-siRNA/LDL-NSC-LA) micelles [199]. Breast cancer cells have a high expression of LDL-receptor and have great sensitivity to LDL micelles. The carboxyl group of NSC-LA provides a reaction with LDL, leading to its attachment to micelles. Although the role of LDL is great, MDR1 siRNAs also plays a remarkable role in cellular uptake of PTX. As it was mentioned, P-gp inhibits the entering of chemotherapeutic agents into cancer cells. MDR1 siRNA results in downregulation in the expression of mdr1 and P-gp, improving the cellular uptake of PTX. Another privilege of CS is providing a platform for conjugation of aptamers. As newly introduced synthetic DNA or RNA molecules, aptamers have demonstrated excellent specificity towards target [200]. Aptamer-conjugated CS NPs enhance the co-delivery of DTX and insulin-like growth factor receptor 1 (IGF-1R) siRNA into breast cancer cells [201]. Anti-mucin 1 (MUC1) was applied as an aptamer due to the upregulation of MUC1 on the breast epithelial cells [202]. CS is not only associated with the biocompatibility of these nanocarriers but also provides a platform for conjugation of the aptamer. By improving the targeted delivery of DTX and IGF-1R siRNA, high cellular uptake of DTX significantly diminishes the viability and proliferation of breast cancer cells and a decrease in cell growth and survival is observed due to inhibition of IGF-1R. Taking everything into account, it seems that CS modification of NPs has two major advantages: A) improving the biocompatibility of NPs, and B) providing a platform for attachment of drugs and genes [203-205].

\section{Imaging and theranostics applications of chitosan here}

NPs have attracted much attention in the field of imaging [186]. Simultaneous imaging and drug delivery are of interest in cancer therapy and NPs provide minimally invasive imaging [206]. In line with this strategy, Bano and colleagues synthesized PTX-loaded magnetic nanocomposites with folate modified CS/carboxymethyl surface [207]. CS served as a platform for loading PTX and folate improved the cellular uptake of NPs through receptor-mediated absorption. Besides, CS provided the stability and protection of drug against degradation or oxidation. It seems that the external magnetic field enhances the anti-tumor activity of these nanocarriers. It is likely that this improvement was caused by controlling the directional 
movement of magnetic carriers via the external field as also reported by Xue et al. [208]. Nevertheless, this finding demonstrates that these NPs have a magnetically guided drug delivery function. Notably, it was found that the high labeling potential of these nanocarriers is a consequence of high cellular uptake due to using CS and folate. CS-stabilized gold NPs (CSAuNPs) are able to be applied for photoacoustic imaging (PAI) of cancer cells [209]. CSAuNPs served as contrast agents and PAI effectively provided image-guided cancer therapy (figure 6). This strategy has demonstrated satisfactory results while using PTX for chemotherapy.

\section{Chitosan nanoparticles for oral delivery of PTX and DTX}

Protection against degradation and improving absorption are two major goals in the oral administration of chemotherapeutic agents such as PTX and DTX by CS nanocarriers (figure 7) [210]. CS-functionalized micelles promote the cellular uptake of PTX through clathrin- and caveolae-mediated endocytosis [173]. Application of amphiphilic CS derivatives such as $\mathrm{N}$ - deoxycholic acid-N, O-Hydroxyethyl CS or carboxymethyl CS is beneficial in the development of NPs for delivery of PTX due to their low molecular weight, resulting in NPs with great properties such as high biocompatibility and excellent potential for drug delivery [211, 212]. Designing N-octyl-N'-phthalyl-O-phosphoryl CS micelles improve the accumulation of PTX in Caco-2 cells through caveolin-mediated endocytosis [213]. However, one of the most challenges of CS NPs is their low cellular uptake in animal models. It seems that 3,b-O, O-dimyristoyl CS (DMC) is not beneficial in improving the absorption of PTX upon oral administration. This drawback is due to the mucoadhesive feature of CS so that DMC NPs make a tough attachment with the mucus layer secreted by HT29-MTX cells, leading to the inhibition of penetration of PTX-loaded CS NPs into cell monolayer [214]. These formulations significantly increase the bioavailability of PTX and subsequently, result in higher anti-tumor activity compared to the PTX alone [215-221]. The same story occurs in DTX delivery. Thiolated CS-functionalized NPs are potential candidates in delivery of DTX [222, 223]. These nanocarriers are associated with enhanced cellular uptake of DTX by opening tight junctions. It is noteworthy to mention that solid lipid NPs (SLNs) enhance the penetration of drugs into the intestinal epithelial layer [224, 225]. With respect to the capability of CS in opening the tight junctions between cells [226, 227], CS-functionalized SLNs are able to incredibly promote the permeabilization of DTX [228]. Notably, in vivo experiments confirm the higher anti-tumor activity of DTX-loaded CS NPs compared to the DTX alone, while these nanocarriers have minimal adverse impacts 
[229]. Conjugation of cyclodextrins (CDs) into CS is an efficient strategy in enhancing the delivery of DTX. This is due to the potential role of CDs in improving the solubility of DTX and protection against degradation, whereas CS opens tight junctions to elevate cellular uptake of DTX [230].

\section{Conclusion and remarks}

At the present review, we described the various CS functionalized-NPs for the delivery of PTX and DTX (table 1,2). NPs can be considered as potential candidates in the delivery of PTX and DTX and have demonstrated great potentials such as high biocompatibility, drug loading, EE and anti-tumor activity. Although the particle size distribution of synthesized CS NPs is uniform, the average particle size should be considered in the following studies. Self-assembled CS micelles can protect PTX and DTX against degradation and release these potent chemotherapeutic agents in a prolonged-release behavior. Similarly, microstructures provide the sustained release of PTX and DTX. It appears that the development of stimuli-responsive NPs provided dramatic progress in cancer therapy and until now, $\mathrm{pH}-$, redox- and thermos-responsive CS NPs have been designed for the delivery of PTX and DTX. An important strategy in enhancing the anti-tumor potential of PTX and DTX is using targeted delivery systems. Folate, TF, and CD44 receptors have been targeted by CS NPs and findings have disclosed satisfactory results in terms of elevating cellular uptake of PTX and DTX. Unfortunately, we have witnessed a significant decrease in the anti-tumor activity of PTX and DTX due to the resistance of cancer cells. As a consequence, CS NPs have been developed in order to simultaneously deliver PTX and DTX with other anti-tumor drugs or genes. One of the most interesting strategies was the application of the MDR1 gene that downregulated P-gp, leading to the high cellular uptake of PTX and DTX by cancer cells. Minimally invasive image-guided delivery and image-guided cancer therapy using PAI are other applications of CS NPs. Besides, CS NPs are of importance in oral delivery of PTX and DTX by protection against degradation at the stomach, sustained-release in intestinal fluid and improving cellular uptake by opening tight junctions. However, more studies are needed to evaluate the efficiency of CS NPs for the delivery of PTX and DTX.

\section{Conflict of interest:}

The authors declare no conflict of interest. 


\section{Figure captions}

Figure 1: The chemical structure of PTX and DOX.

Figure 2: The mechanism of action of PTX and DTX. During the physiological condition, there is a balance in entering and eliminating of tubulin proteins from microtubules. Upon administration of PTX or DTX, this balance is interrupted, and microtubules obtain a stabilized form, resulting in inhibition of mitosis and apoptotic cell death.

Figure 3: Stimuli-responsive CS NPs for delivery of PTX and DTX, and their mechanism of action.

Figure 4: Various CS-functionalized NPs applied in the delivery of PTX and DTX.

Figure 5: CNTs as potential candidates in the delivery of PTX and DTX.

Figure 6: The application of CS-functionalized NPs in cancer imaging and theranostics.

Figure 7: Protection against degradation in the stomach and enhancing the absorption of PTX and DTX through the intestine by CS NP 
Table 1: Chitosan-based delivery systems for PTX.

\begin{tabular}{|c|c|c|c|c|c|c|c|c|}
\hline Components & Structures & $\begin{array}{l}\text { Loading } \\
\text { capacity }\end{array}$ & $\begin{array}{l}\text { Release } \\
\text { properties }\end{array}$ & $\begin{array}{l}\text { Targe } \\
\text { ting } \\
\text { agents }\end{array}$ & $\begin{array}{l}\text { Co- } \\
\text { deliver } \\
\text { ed } \\
\text { agents }\end{array}$ & $\begin{array}{l}\text { Cancer } \\
\text { cell } \\
\text { lines/in } \\
\text { vivo }\end{array}$ & Major outcomes & Refs \\
\hline $\begin{array}{l}\text { Deoxycholic acid- } \\
\text { O- } \\
\text { carboxymethylated } \\
\text { CS-FA }\end{array}$ & Micelle & $33.61 \%$ & $\begin{array}{l}100 \% \text { of the } \\
\text { nonencapsulated } \\
\text { drug was } \\
\text { released } \\
\text { after 24 hours }\end{array}$ & FA & & $\begin{array}{l}\text { MCF-7 } \\
\text { cells, }\end{array}$ & $\begin{array}{l}\text { Cytotoxicity of the micelles contain } \\
\text { folate was considerably more than the } \\
\text { micelles without folate or the } \\
\text { injection of PTX (commercially } \\
\text { available) }\end{array}$ & [147] \\
\hline
\end{tabular}




\begin{tabular}{|c|c|c|c|c|c|c|}
\hline $\begin{array}{l}\text { CS-Ceramide } \\
\text { Nanoparticle }\end{array}$ & $\begin{array}{l}\text { Polymeric } \\
\text { nanoparticle }\end{array}$ & $\begin{array}{l}\text { Loading } \\
\text { efficiency } \\
=96.9 \% \\
\text { and } \\
\text { Loading } \\
\text { capacity= } \\
12.1 \% .\end{array}$ & $\begin{array}{ll}30 \% & \text { PTX is } \\
\text { released after } & 48 \mathrm{~h} .\end{array}$ & $\begin{array}{l}\text { B16F10 and } \\
\text { MCF-7 }\end{array}$ & $\begin{array}{l}\text { The polymeric nanoparticle of CS- } \\
\text { CE could be used as a nanocarrier for } \\
\text { oral delivery of hydrophobic drugs. }\end{array}$ & {$[220]$} \\
\hline $\begin{array}{l}\text { CS stabilized } \\
\text { multilayered } \\
\text { liposomes }\end{array}$ & $\begin{array}{l}\text { Multilayere } \\
\text { d liposomes }\end{array}$ & $10 \mathrm{wt} \%$ & $\begin{array}{l}42 \% \text { in } 1 \mathrm{~h} \text { and } \\
69 \% \text { in } 4 \mathrm{~h} \text {. }\end{array}$ & HeLa & $\begin{array}{l}\text { The prepared multilayered } \\
\text { liposomes induced cytotoxicity in } \\
\text { cancer cells compared to PTX- } \\
\text { liposomes }\end{array}$ & [231] \\
\hline $\begin{array}{l}\mathrm{CS} / \beta- \\
\text { Glycerophosphate }\end{array}$ & Hydrogel & & $\begin{array}{l}\text { The release } \\
\text { the } 1 \quad \mathrm{mg} / \mathrm{mL} \\
\text { loaded gel was } \\
92.85 \%, \\
\mathrm{mg} / \mathrm{mL} \quad \text { loaded }\end{array}$ & $\begin{array}{l}\text { Murine } \mathrm{H} 22 \\
\text { hepatoma } \\
\text { cells/ Male } \\
\text { ICR mice }\end{array}$ & $\begin{array}{l}\text { Administration of prepared } \\
\text { hydrogel was an effective targeting } \\
\text { treatment strategy for tumor. }\end{array}$ & [136] \\
\hline
\end{tabular}




\begin{tabular}{|c|c|c|c|c|c|c|}
\hline & & & $\begin{array}{l}\text { gel was } 76.68 \% \\
\text { (After } 21 \text { days) }\end{array}$ & & & \\
\hline CS nanoparticles & $\begin{array}{l}\text { Nanoparticl } \\
\text { es }\end{array}$ & $8-12 \%$ & $\begin{array}{l}68-83 \% \text { of the } \\
\text { drug within } 12 \mathrm{~h}\end{array}$ & $\begin{array}{l}\text { MDA-MB- } \\
231 \quad \text { as a } \\
\text { model } \\
\text { breast } \\
\text { cancer cell } \\
\text { line }\end{array}$ & $\begin{array}{l}\text { An increase of } 20 \% \text { growth } \\
\text { inhibition by docetaxel loaded CS } \\
\text { nanoparticles compared to the free } \\
\text { drug after } 72 \mathrm{~h} .\end{array}$ & [84] \\
\hline $\begin{array}{l}\text { CS-g-poly( } \varepsilon- \\
\text { caprolactone) } \\
\text { polymer }\end{array}$ & & & Steady release & & $\begin{array}{l}\text { Release rates were improved for } \\
\text { implants modified with } \mathrm{CP}(\mathrm{CS}-\mathrm{g}- \\
\text { poly( } \varepsilon \text {-caprolactone }) \quad \text { additives, } \\
\text { Drug release kinetics showed that }\end{array}$ & [232] \\
\hline
\end{tabular}




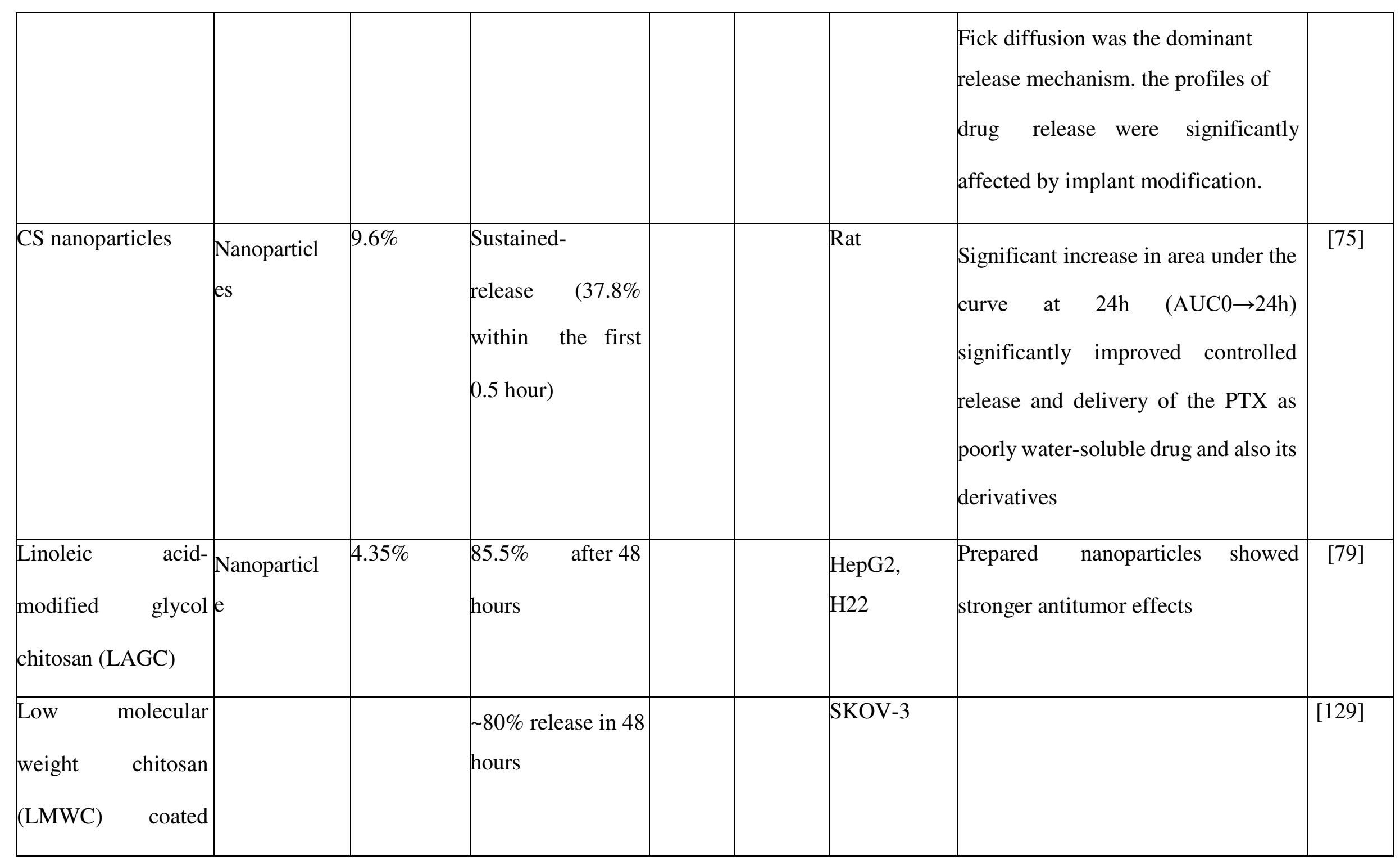




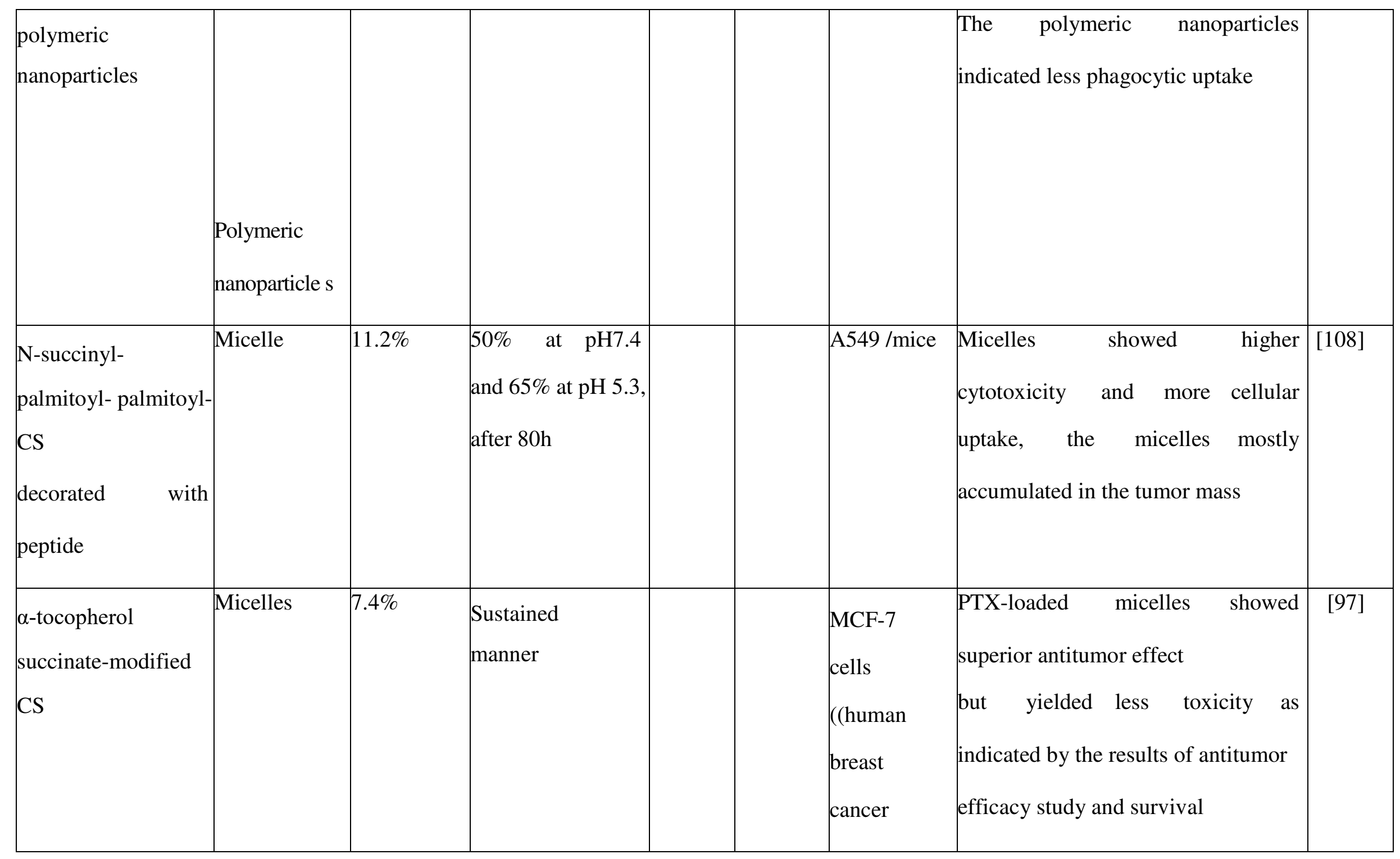




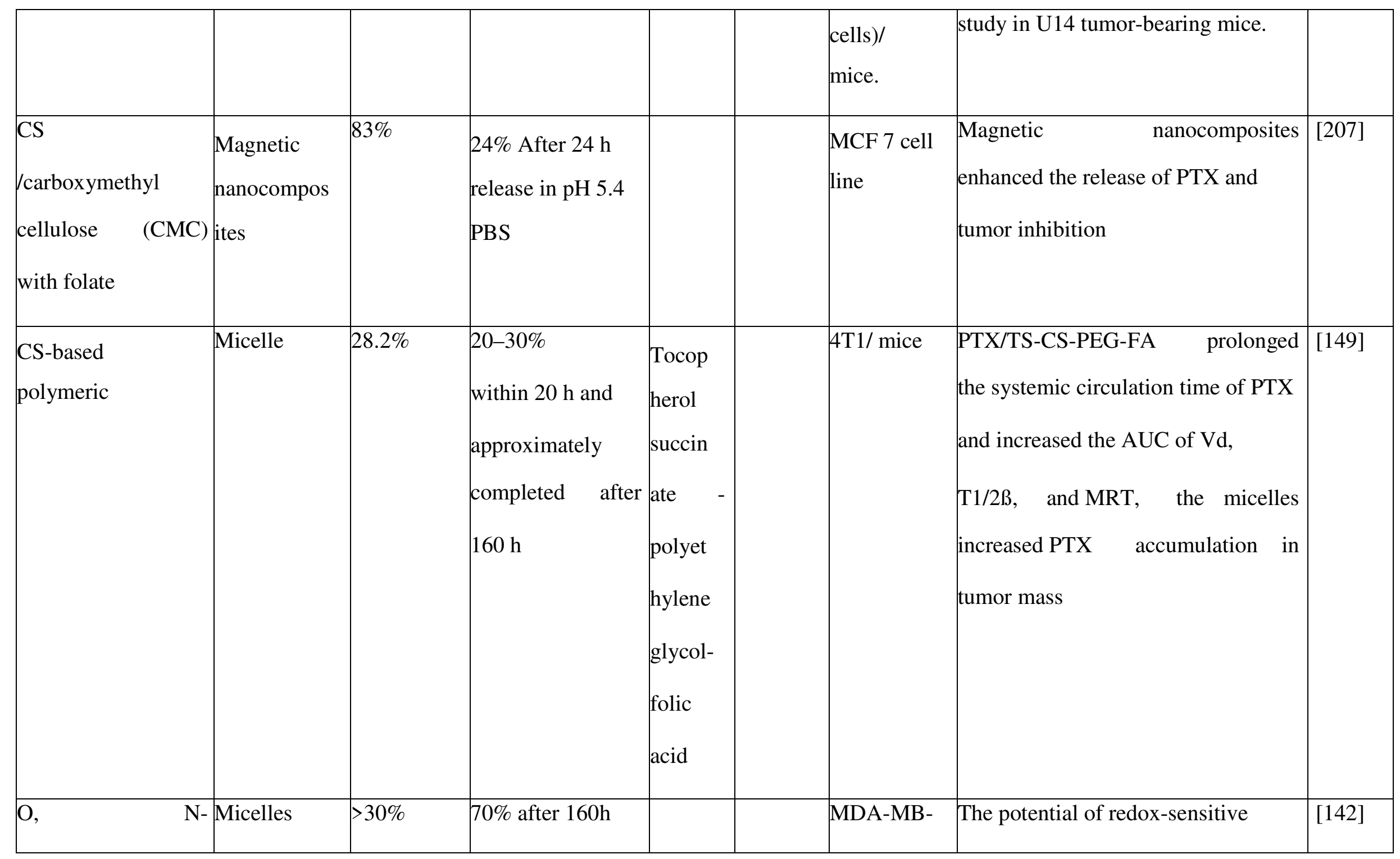




\begin{tabular}{|c|c|c|c|c|c|c|c|}
\hline $\begin{array}{l}\text { hydroxyethylchitos } \\
\text { an-octylamine }\end{array}$ & & & & & $231 /$ mice & $\begin{array}{llr}\text { micelles for } & \text { intracellular } \\
\text { transportation } & \text { of } & \text { lipophilic } \\
\text { anticancer drugs } & & \end{array}$ & \\
\hline $\begin{array}{l}\text { CS } \\
\text { oligosaccharide- } \\
\text { stabilized gold } \\
\text { nanoparticles }\end{array}$ & es & $82.71 \%$ & $19 \%$ in the first 3 & & $\begin{array}{l}\text { MDA-MB- } \\
231\end{array}$ & $\begin{array}{l}\text { Use of prepared nanoparticles for } \\
\text { drug delivery and also } \\
\text { photoacoustic imaging of cancer } \\
\text { cells. }\end{array}$ & [209] \\
\hline CS Nanoparticles & es & & & & $\begin{array}{l}\text { MCF-7and } \\
\text { human } \\
\text { fibroblast } \\
\text { primary } \\
\text { cell }\end{array}$ & $\begin{array}{l}\text { The decrease in BAX and BCL-2 } \\
\text { gene expressions in nanoparticle } \\
\text { treated cells in comparison to intact } \\
\text { cells, elevating the BAX/BCL-2 } \\
\text { ratio compared with free drug- } \\
\text { treated cells. }\end{array}$ & [85] \\
\hline $\begin{array}{l}\text { CS-PEG } \\
\text { nanoparticles }\end{array}$ & Nanoparticl & over $50 \%$ & $\begin{array}{l}67.14 \pm 0.9 \text { and } \\
69.64 \pm 0.5 \% \text { up } \\
\text { to } 48 \mathrm{~h} \text { in PBS }\end{array}$ & $\begin{array}{l}\text { Transf } \\
\text { errin } \\
\text { recept }\end{array}$ & $\begin{array}{l}\text { HOP-62/ } \\
\text { rat }\end{array}$ & $\begin{array}{l}\text { Prepared nanoparticles enhanced } \\
\text { the therapeutic action, showed } \\
\text { sustained release profile, higher }\end{array}$ & [155] \\
\hline
\end{tabular}




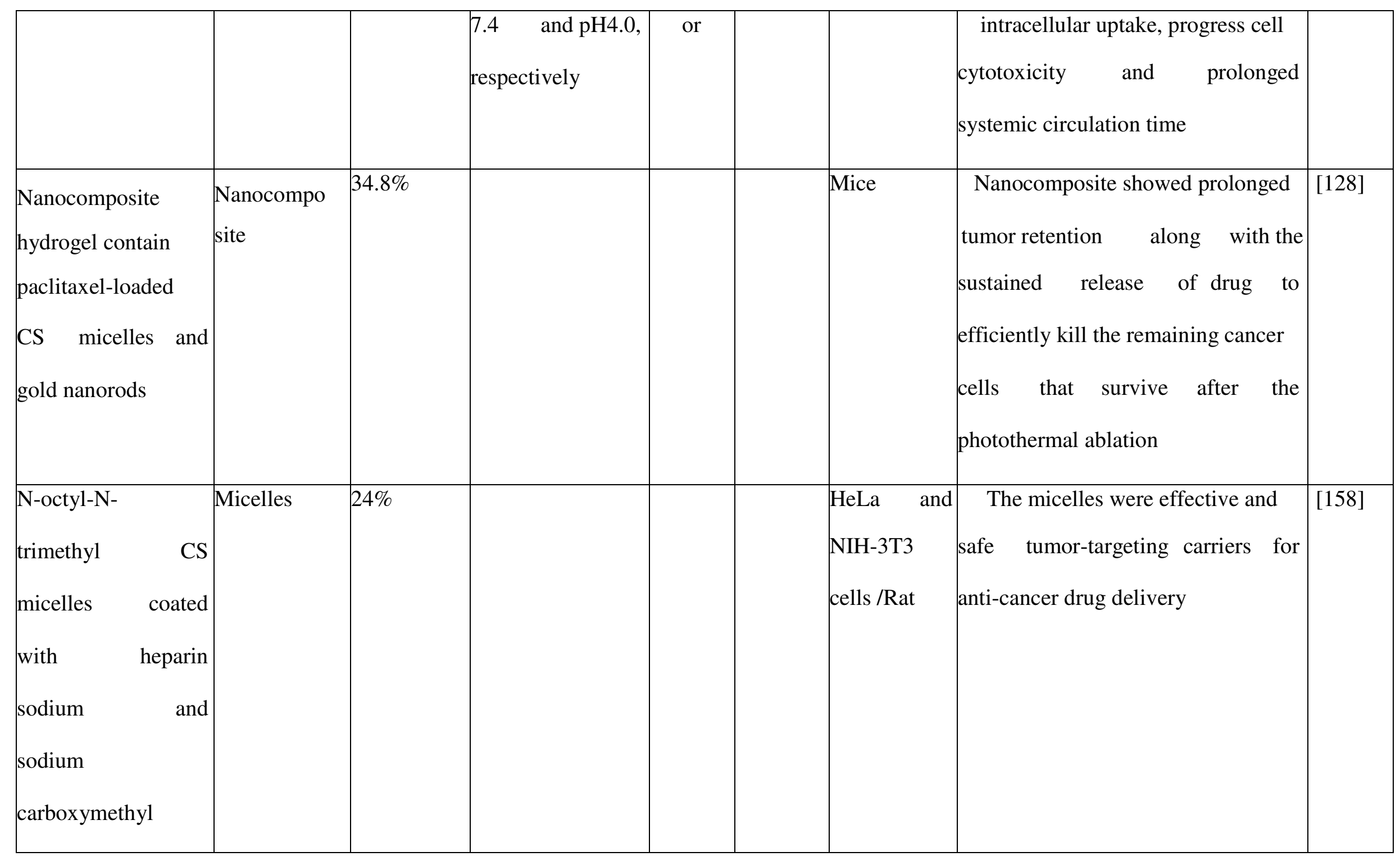




\begin{tabular}{|c|c|c|c|c|c|c|}
\hline $\begin{array}{ll}\text { cellulose } & \text { (anionic } \\
\text { polymers) } & \end{array}$ & & & & & & \\
\hline hydroxypropyl & Nanoparticl & $2.55 \%$ & $22 \%, 60 \%$ at $\mathrm{pH}$ & Rats & Nanoparticles & {$[228]$} \\
\hline
\end{tabular}




\begin{tabular}{|c|c|c|c|c|c|c|}
\hline $\begin{array}{l}\text { trimethyl ammonium } \\
\text { chloride } \\
\text { modified } \\
\text { lipid nanoparticles }\end{array}$ & es & & $\begin{array}{l}1.2 \text { was lower } \\
\text { than that at } \mathrm{pH} 6.8 \\
\text { after } 24 \mathrm{~h}\end{array}$ & & bioavailability of DTX & \\
\hline $\begin{array}{l}\text { Vitamin } \\
\text { succinate-grafted- } \\
\mathrm{CS} \\
\text { oligosaccharide } \\
\text { RGD-conjugated } \\
\text { D-alpha- } \\
\text { tocopheryl PEG }\end{array}$ & Micelles & $5.92 \%$ & $27 \%$ after $4 \mathrm{~h}$ & U87MG & $\begin{array}{l}\text { The prepared micelles have non- } \\
\text { toxic on normal cells. The tumor } \\
\text { inhibitory rate of the prepared } \\
\text { micelles and free drug in the } \\
\text { treatment tumor was } 88.4 \% \text { and } \\
49.3 \% \text {, respectively. }\end{array}$ & [102] \\
\hline $\begin{array}{l}\text { FA-cholesterol-CS } \\
\text { micelles }\end{array}$ & Micelles & $9.1 \%$ & $\begin{array}{l}\text { Almost } 85 \% \text { at } \mathrm{pH} \\
5.0 \text { and } 76 \% \text { at } \mathrm{pH} \\
7.4\end{array}$ & Hela & $\begin{array}{l}\text { The cytotoxic effect of prepared } \\
\text { micelles was higher than that of free } \\
\text { Taxol. }\end{array}$ & {$[148]$} \\
\hline CS nanoparticle & Nanoparticl & 0.345 & release & MDA-MB- & Treatment with nanoparticles & [70] \\
\hline
\end{tabular}




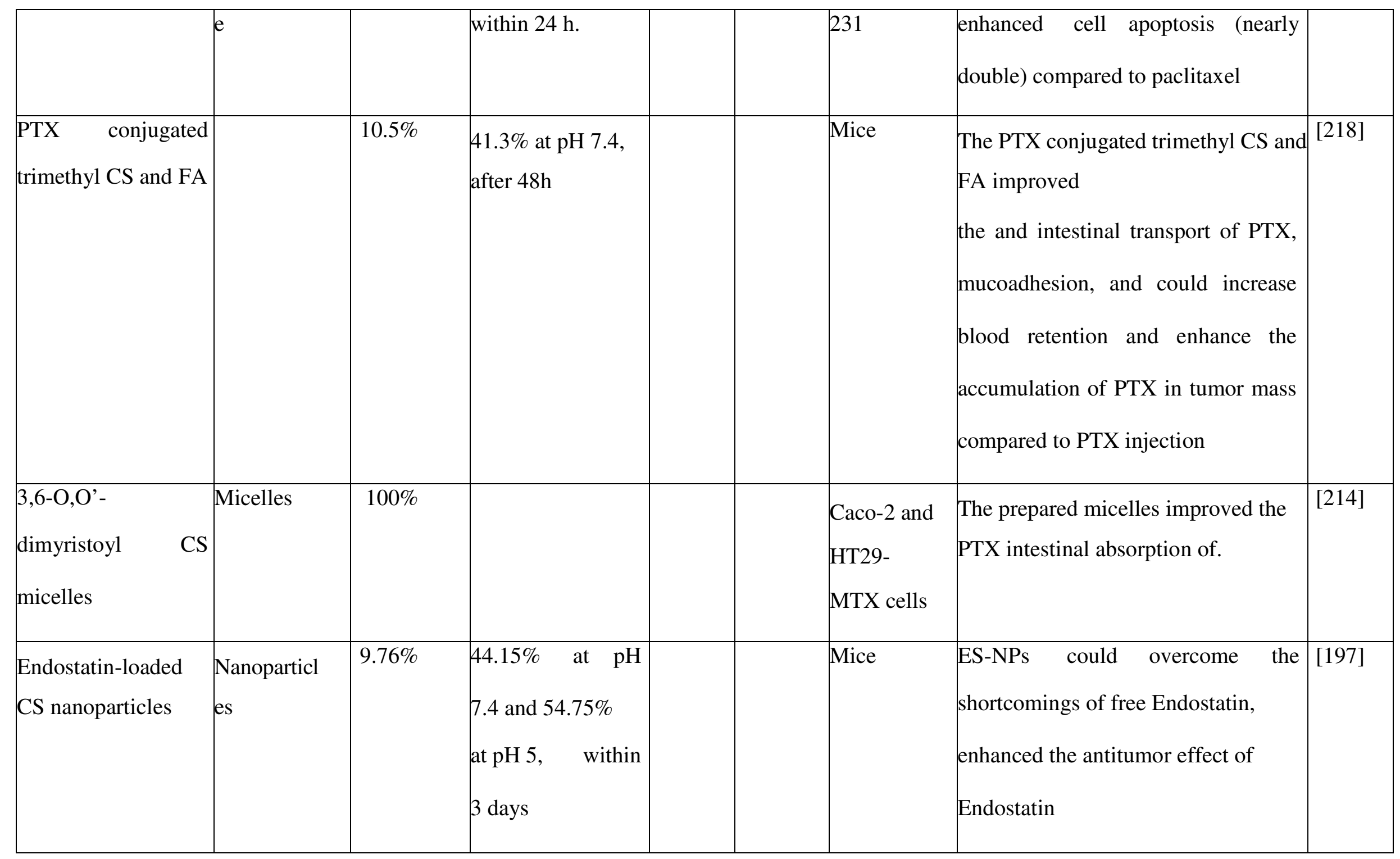




\begin{tabular}{|c|c|c|c|c|c|c|}
\hline $\begin{array}{l}\text { N-deoxycholic } \\
\text { acid-N, } \quad \text { O- } \\
\text { hydroxyethyl CS }\end{array}$ & Micelles & -30 wt\% & $\begin{array}{l}1.5 \% \text { during } 2 \mathrm{~h} \\
\text { in an artificial } \\
\text { gastric juice at } \\
\mathrm{pH} 1.2 \text { and } 5.0 \% \\
\text { within } 22 \mathrm{~h} \text { in } \\
\text { the intestinal } \\
\text { fluid at } \mathrm{pH} 6.8\end{array}$ & $\begin{array}{l}\text { Caco-2 } \\
\text { cells/Rat }\end{array}$ & $\begin{array}{l}\text { Micelles overcame the low } \\
\text { bioavailability- the most prominent } \\
\text { barrier to oral PTX efficacy. }\end{array}$ & [217] \\
\hline $\begin{array}{l}\text { N Succinyl } \\
\text { Hydroxyethyl } \\
\text { CS Film }\end{array}$ & Film & & $\begin{array}{l}10 \% \text { of PTX in the } \\
\text { first } 2 \text { weeks }\end{array}$ & Rabbit & $\begin{array}{l}\text { PTX SHEC film effectively } \\
\text { inhibits the myofibroblast } \\
\text { proliferation and extracellular } \\
\text { matrix over deposition during the } \\
\text { the healing process of biliary } \\
\text { reconstruction }\end{array}$ & [233] \\
\hline $\begin{array}{l}\text { CS-grafted- } \\
\text { polycaprolactone } \\
\text { micelles }\end{array}$ & Micelles & $\begin{array}{l}\text { Almost } \\
5 \%\end{array}$ & & $\begin{array}{l}\text { Caco-2, } \\
\text { HT29- } \\
\text { MTX }\end{array}$ & $\begin{array}{l}\text { Permeability of PTX was higher in } \\
\text { prepared micelles compared with } \\
\text { monolayer due to the mucoadhesive }\end{array}$ & [101] \\
\hline
\end{tabular}




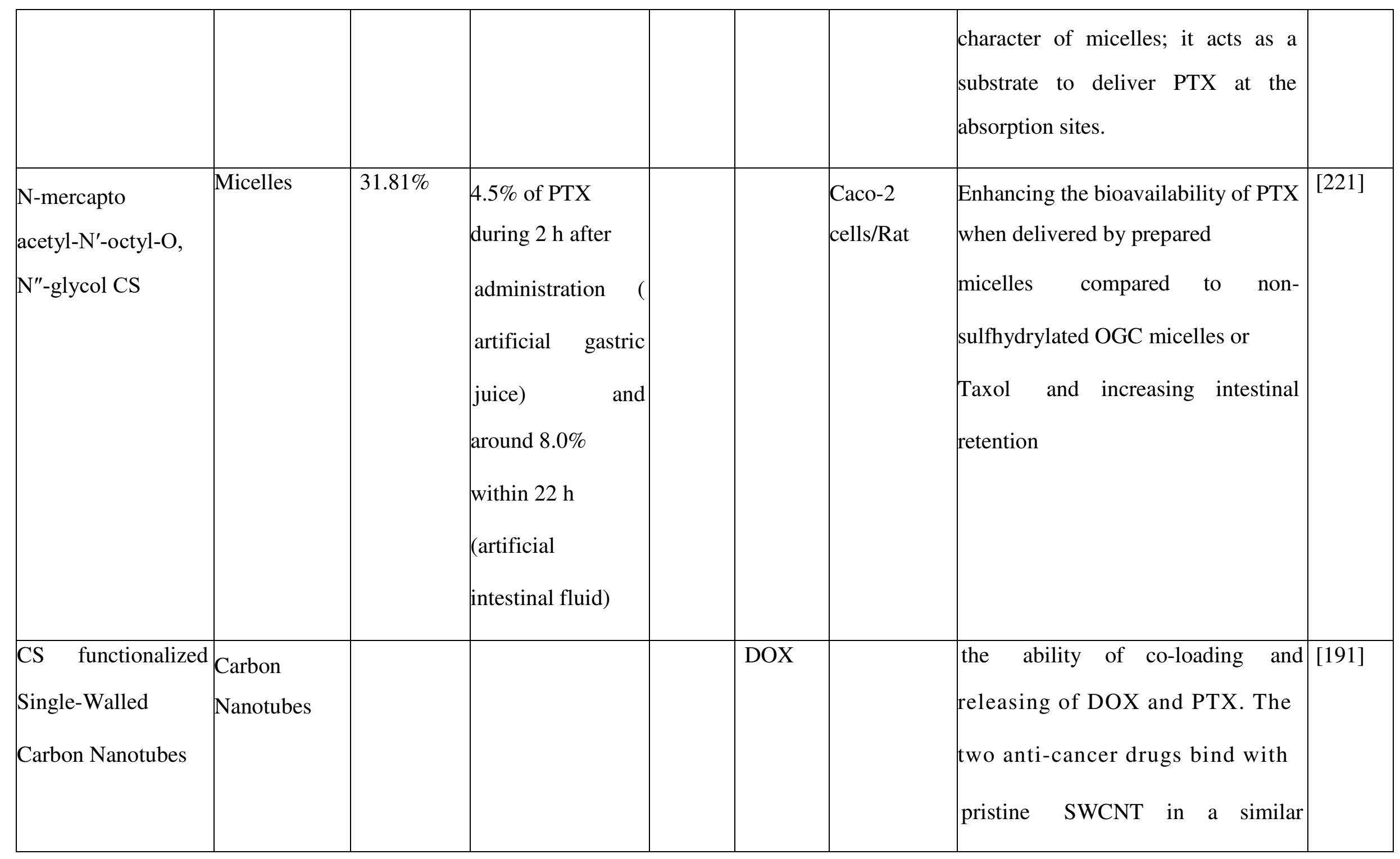




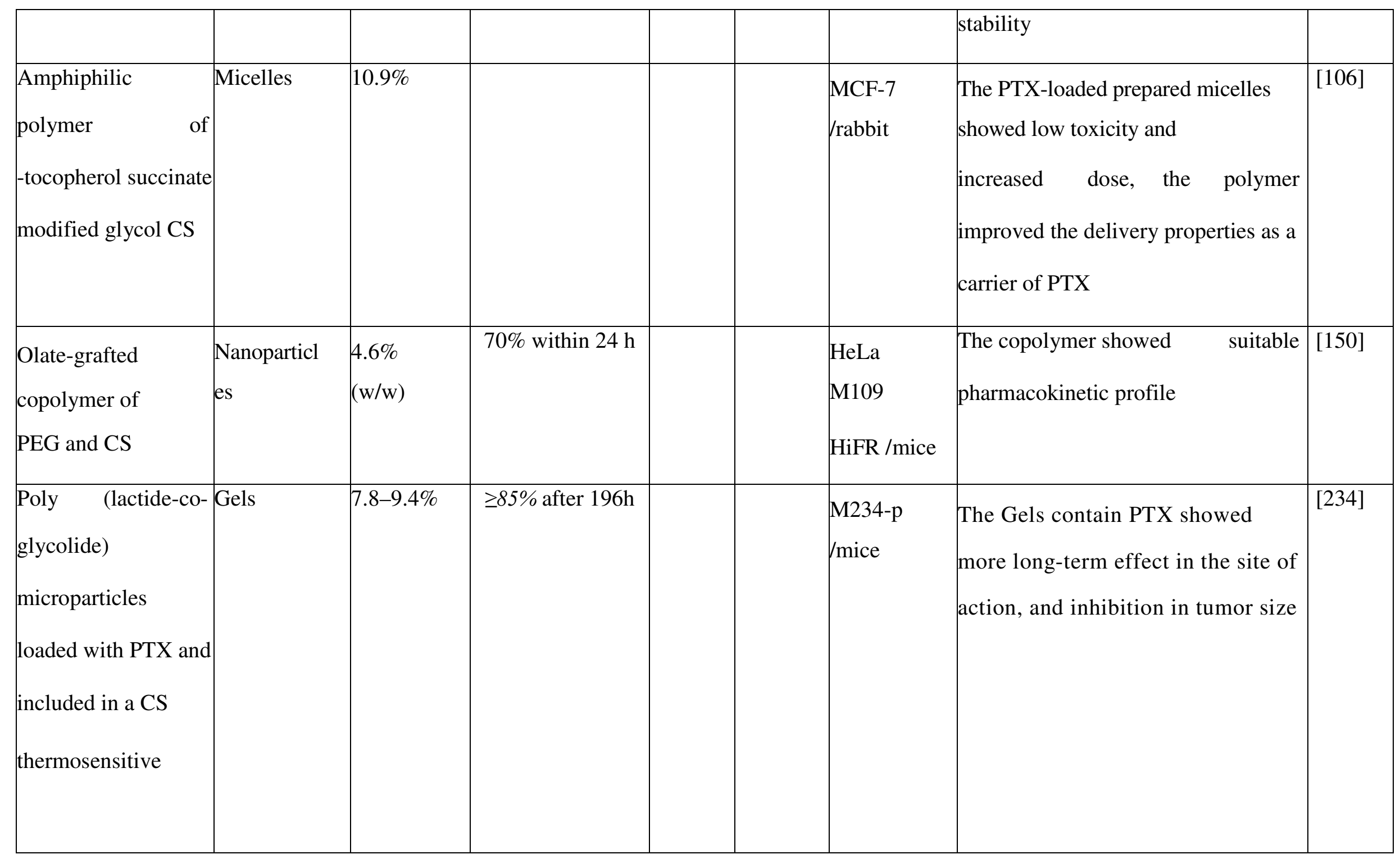




\begin{tabular}{|c|c|c|c|c|c|c|}
\hline gelling solution & & & & & & \\
\hline $\begin{array}{l}\text { N-octyl-N'- } \\
\text { phthalyl-O- } \\
\text { phosphoryl CS } \\
\text { derivative }\end{array}$ & Micelles & $\begin{array}{l}51.23 \% \\
\text { (wt \%) }\end{array}$ & $\begin{array}{l}\text { less than } 20 \% \\
\text { after } 24 \mathrm{~h}\end{array}$ & $\begin{array}{l}\text { Caco-2 } \\
\text { cells }\end{array}$ & $\begin{array}{l}\text { Efficient accumulation and } \\
\text { transport of prepared micelles } \\
\text { loading rhodamine-123 or PTX into } \\
\text { the cells by clathrin/cavelin- } \\
\text { mediated endocytosis }\end{array}$ & [213] \\
\hline $\begin{array}{l}\text { Glycol CS } \\
\text { nanoparticles }\end{array}$ & $\begin{array}{l}\text { Nanoparticl } \\
\text { es }\end{array}$ & & Slow-release & HeLa cells & $\begin{array}{l}\text { PTX-loaded nanoparticles with } 400 \\
\text { nm particle size, low PDI and } \\
\text { positive charge. They could be } \\
\text { internalized by cell lines, probably by } \\
\text { endocytosis }\end{array}$ & [72] \\
\hline
\end{tabular}




\begin{tabular}{|c|c|c|c|c|c|c|}
\hline $\begin{array}{l}\text { Carboxymethyl } \\
\text { CS- polymeric } \\
\text { micelles }\end{array}$ & Micelles & $35.24 \%$ & $\begin{array}{l}19.62 \% \text { of the } \\
\text { loaded PTX in } \\
\text { simulated gastric } \\
\text { fluid / intestinal } \\
\text { fluid } \\
\text { and } 66.14 \% \\
\text { PBS during } 48 \mathrm{~h}\end{array}$ & $\begin{array}{l}\text { MCF-7 and } \\
\text { Caco-2 } \\
\text { cells/rat }\end{array}$ & $\begin{array}{l}\text { Prepared micelles were favorable for } \\
\text { oral delivery of water-insoluble } \\
\text { anticancer drugs. }\end{array}$ & {$[212]$} \\
\hline
\end{tabular}


Table 2: CS-based delivery systems for DTX.

\begin{tabular}{|c|c|c|c|c|c|c|c|c|}
\hline Components & Structures & $\begin{array}{l}\text { Loading } \\
\text { capacity }\end{array}$ & $\begin{array}{l}\text { Release } \\
\text { properties }\end{array}$ & $\begin{array}{l}\text { Targeting } \\
\text { agents }\end{array}$ & $\begin{array}{l}\text { Co- } \\
\text { delivered } \\
\text { agents }\end{array}$ & $\begin{array}{l}\text { Cancer } \\
\text { cell lines }\end{array}$ & Major outcomes & Refs \\
\hline $\begin{array}{l}\text { CS cross-linked y-poly } \\
\text { (glutamic acid) } \\
\text { nanoparticles }\end{array}$ & $\begin{array}{l}\text { biopolymeric } \\
\text { nanoparticles }\end{array}$ & & & $\begin{array}{l}\text { Epidermal } \\
\text { growth } \\
\text { factor }\end{array}$ & $\begin{array}{l}\text { Cetuximab } \\
\text { (CET) }\end{array}$ & $\begin{array}{l}\text { A549 (Non- } \\
\text { small- cell } \\
\text { lung } \\
\text { carcinoma) } \\
\text { and } \\
\text { NIH3T3 } \\
\text { (mouse } \\
\text { embryonic } \\
\text { fibroblasts } \\
\text { cells) }\end{array}$ & $\begin{array}{l}\text { A G2/M phase cell cycle } \\
\text { arrest in The A549 cells } \\
\text { treated with nanoparticles, } \\
\text { reduction of mitochondrial } \\
\text { membrane potential, } \\
\text { induction of necrosis and } \\
\text { apoptosis leads to an } \\
\text { increase in cancer cell death. }\end{array}$ & [164] \\
\hline CS Microspheres & Microsphere & 18.7 & sustained- & & & Rats & By using the microsphere & [119] \\
\hline
\end{tabular}




\begin{tabular}{|c|c|c|c|c|c|c|c|}
\hline & & & $\begin{array}{l}\text { release } \\
80 \% \quad \text { in } \\
\text { the first } 12 \\
\text { h) }\end{array}$ & & mice & $\begin{array}{l}\text { DTX accumulates in the } \\
\text { target site while decreasing } \\
\text { the drug accumulation in } \\
\text { healthy tissue }\end{array}$ & \\
\hline $\begin{array}{l}\text { CS/Sulfobutylether- } \beta- \\
\text { Cyclodextrin Nanoparticles }\end{array}$ & Nanoparticles & $0.36 \%$ & $\begin{array}{l}40 \% \text { in the } \\
\text { first } 12\end{array}$ & $\begin{array}{l}\text { Berbamine } \\
\text { (A natural } \\
\text { isoquinoline } \\
\text { alkaloid) }\end{array}$ & $\begin{array}{l}\text { MCF-7 } \\
\text { (Human } \\
\text { breast } \\
\text { cancer } \\
\text { cells) /Rat }\end{array}$ & $\begin{array}{l}\text { A better controlled-release } \\
\text { property } \\
\text { and an enhanced intestine } \\
\text { absorption property of the } \\
\text { dual-drug CD/CS NPs. } \\
\text { higher cellular uptake, } \\
\text { cytotoxicity and apoptosis } \\
\text { rate }\end{array}$ & [195] \\
\hline CS nanoparticles & Nanoparticles & 12.01 & $\left|\begin{array}{ll}73.79 \% & \\
\text { over } & \text { a } \\
\text { period } & \text { of }\end{array}\right|$ & & $\begin{array}{l}\text { Breast } \\
\text { cancer } \\
\text { (MDA- }\end{array}$ & $\begin{array}{l}\text { Improving therapeutic } \\
\text { effects and reducing toxicity }\end{array}$ & [235] \\
\hline
\end{tabular}




\begin{tabular}{|c|c|c|c|c|c|c|c|}
\hline & & & $24 \mathrm{~h}$ & & MB-231) & & \\
\hline $\begin{array}{l}\text { CS coated hyaluronic } \\
\text { acid-docetaxel }\end{array}$ & Nanoparticles & $62.78 \%$ & & HA & $\begin{array}{l}\text { MCF-7 } \\
\text { and } \\
\text { T1 cell } \\
\text { lines }\end{array}$ & $\begin{array}{l}\text { The prepared nanoparticles } \\
\text { were more effective against } \\
\text { cancer cells in comparison } \\
\text { with free DTX. }\end{array}$ & [236] \\
\hline $\begin{array}{l}\text { CS-functionalized } \\
\text { single-walled carbon } \\
\text { nanotube }\end{array}$ & $\begin{array}{l}\text { Carbon } \\
\text { nanotube }\end{array}$ & $32.04 \%$ & $\mid \begin{array}{l}(68 \%) \\
\mathrm{pH} 5.0 \text { and } \\
(49 \%) \quad \text { at } \\
\text { pH 7.4. }\end{array}$ & & $\begin{array}{l}\text { A549 } \\
\text { tumor } \\
\text { cells/mice }\end{array}$ & $\begin{array}{l}\text { Carbon nanotube showed } \\
\text { high drug loading, pH- } \\
\text { responsive drug release, } \\
\text { Significant antitumor effect as } \\
\text { well as good safety to the } \\
\text { body. }\end{array}$ & {$[184]$} \\
\hline Biotinylated CS & Nanocochleates & & $57 \%$ after 72 & & $\begin{array}{l}\text { Breast } \\
\text { cancer } \\
\text { MCF-7 } \\
\text { cells }\end{array}$ & $\begin{array}{l}\text { Increasing bioavailability of } \\
\text { DTX from prepared } \\
\text { Nanocochleates by 10-folds } \\
\text { with longer circulation time } \\
\text { and slower speed of }\end{array}$ & {$[165]$} \\
\hline
\end{tabular}




\begin{tabular}{|c|c|c|c|c|c|c|c|}
\hline & & & & & & $\begin{array}{l}\text { elimination accompanied by } \\
\text { low tissue distribution as } \\
\text { compared } \\
\text { to free DTX }\end{array}$ & \\
\hline $\begin{array}{l}\text { CS-Coated } \\
\text { Liposomes }\end{array}$ & Liposomes & $11.85 \%$ & $\begin{array}{l}70 \% \\
\text { released } \\
\text { within } \\
12 \mathrm{~h}\end{array}$ & & $\begin{array}{l}\text { Human } \\
\text { colon } \\
\text { cancer } \\
\text { (HT-29) } \\
\text { cells /rat }\end{array}$ & $\begin{array}{l}\text { The prepared liposomes } \\
\text { effect on the } \\
\text { pharmacokinetic parameters } \\
\text { cytotoxic efficiency } \\
\text { compared with those of the } \\
\text { uncoated ones }\end{array}$ & [237] \\
\hline
\end{tabular}




\begin{tabular}{|c|c|c|c|c|c|c|c|}
\hline CS nanoparticle & Nanoparticle & $\begin{array}{l}50 \% \text { of } \\
\text { their } \\
\text { contents } \\
\text { (siRNA or } \\
\text { DTX) in first } 36 \\
\text { h. }\end{array}$ & $\begin{array}{l}\text { Anti- } \\
\text { MUC1 } \\
\text { aptamer }\end{array}$ & $\begin{array}{l}\text { IGF-1R } \\
\text { Silencer } \\
\text { siRNA }\end{array}$ & $\begin{array}{l}\text { SKBR3 } \\
\text { cells }\end{array}$ & $\begin{array}{l}\text { Aptamer-conjugated NPs } \\
\text { dramatically reduced the } \\
\text { genetic expression of IGF- } \\
1 \mathrm{R}, \quad \text { matrix } \\
\text { metalloproteinase-9, STAT3, } \\
\text { and VEGF. }\end{array}$ & [201] \\
\hline
\end{tabular}



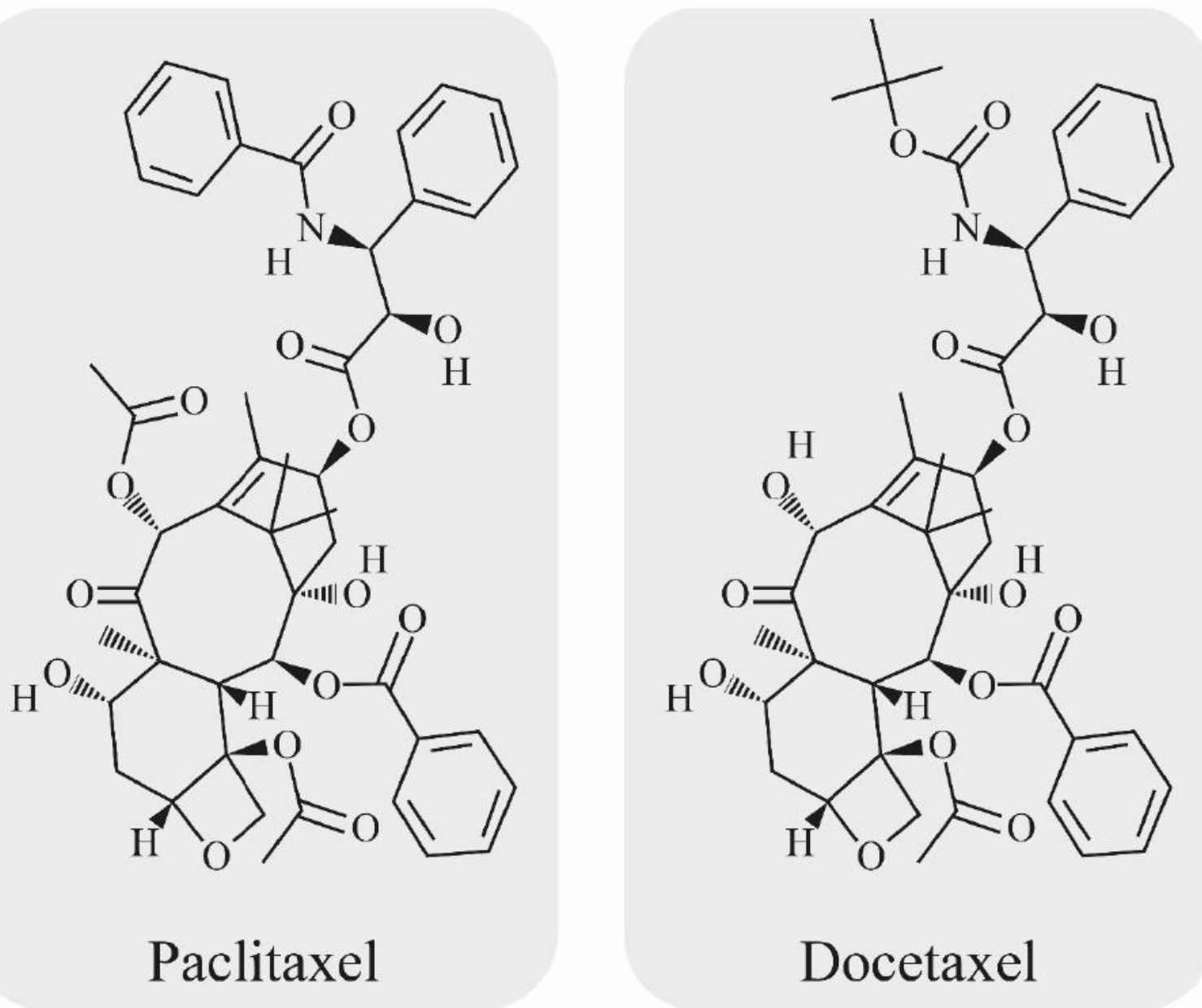

Figure 1: The chemical structure of PTX and DOX. 

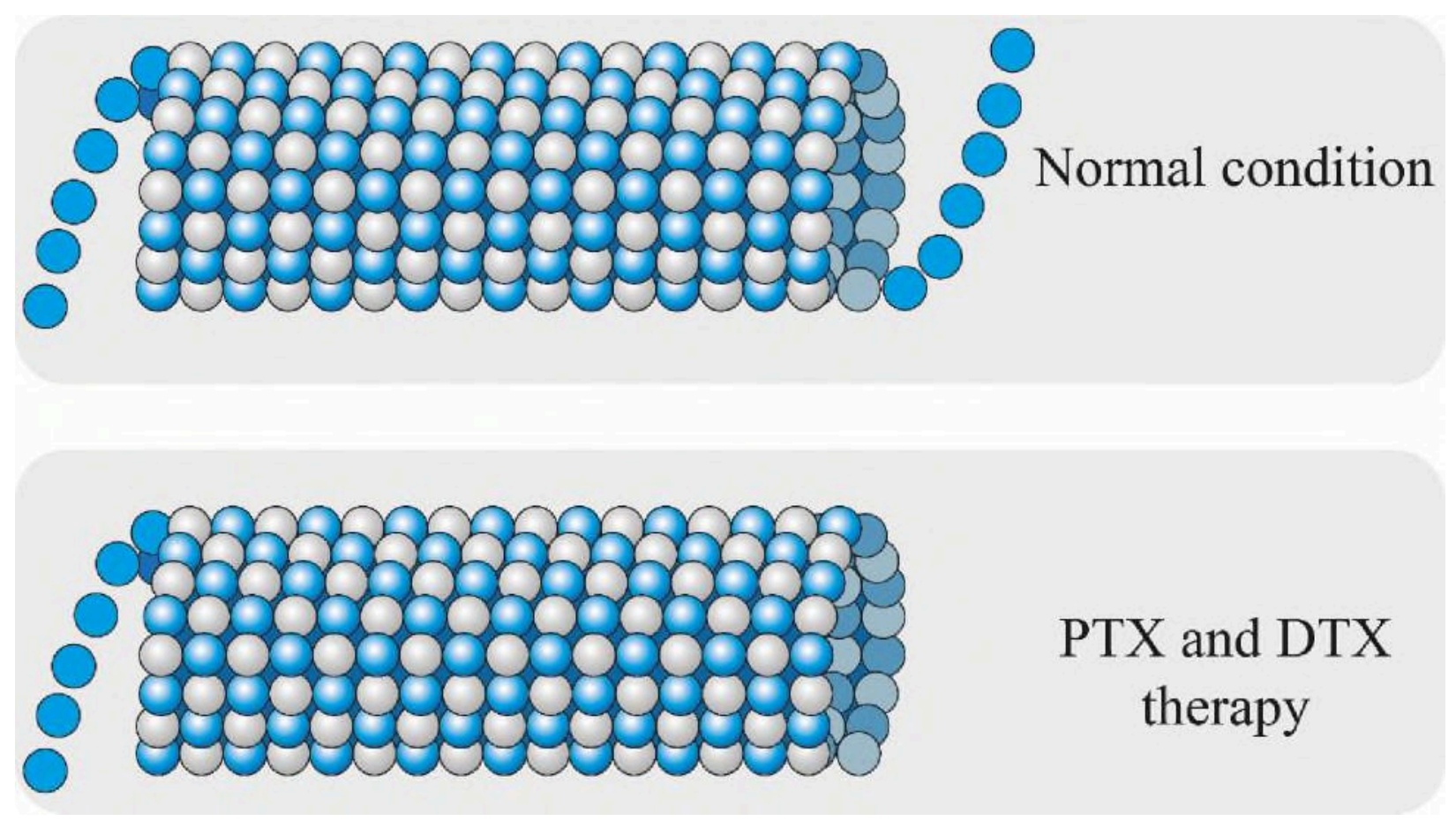

Figure 2: The mechanism of action of PTX and DTX. During the physiological condition, there is a balance in entering and eliminating of tubulin proteins from microtubules. Upon administration of PTX or DTX, this balance is interrupted, and microtubules obtain a stabilized form, resulting in inhibition of mitosis and apoptotic cell death. 


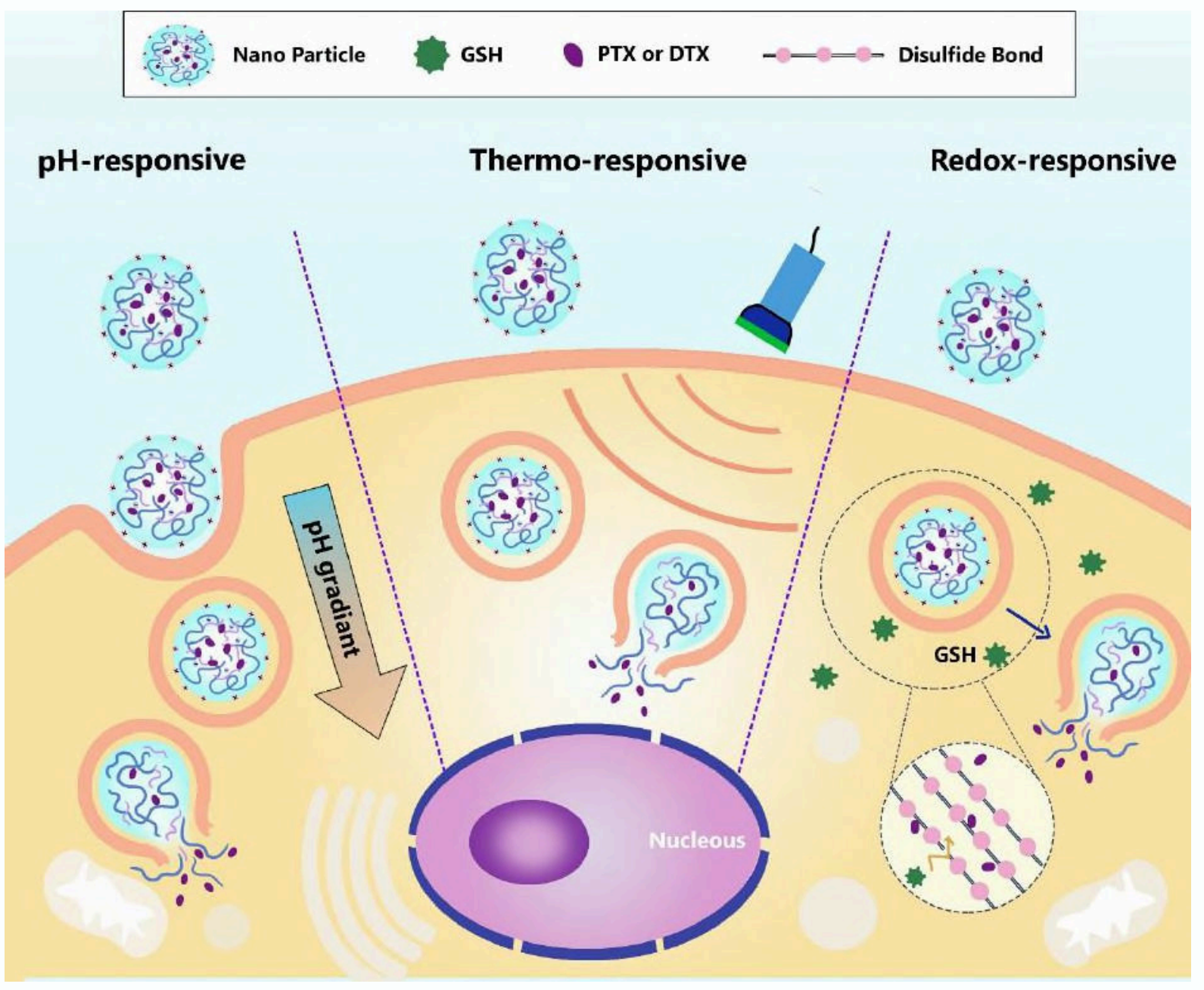

Figure 3: Stimuli-responsive CS NPs for delivery of PTX and DTX, and their mechanism of action. 


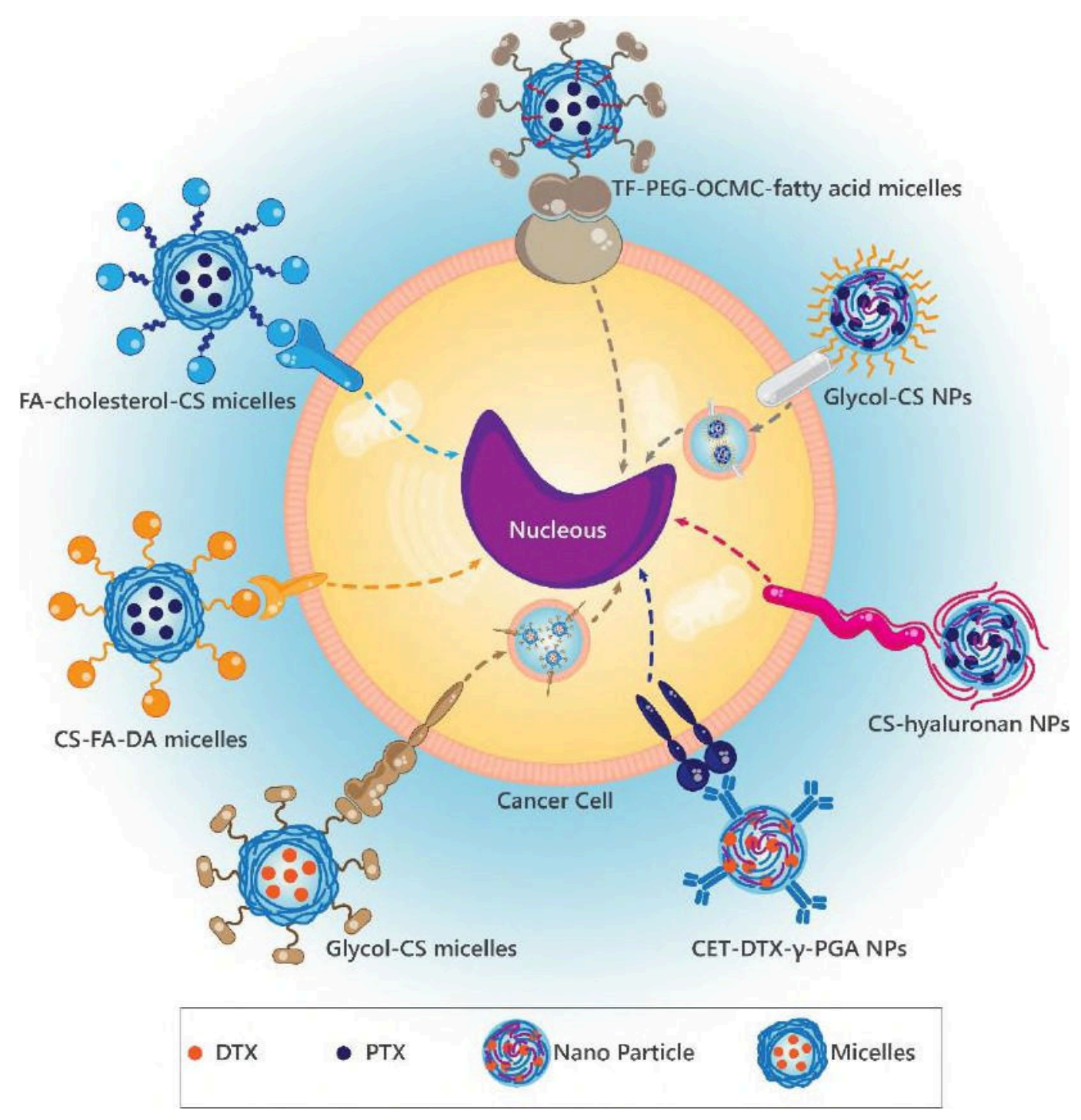

Figure 4: Various CS-functionalized NPs applied in the delivery of PTX and DTX. 

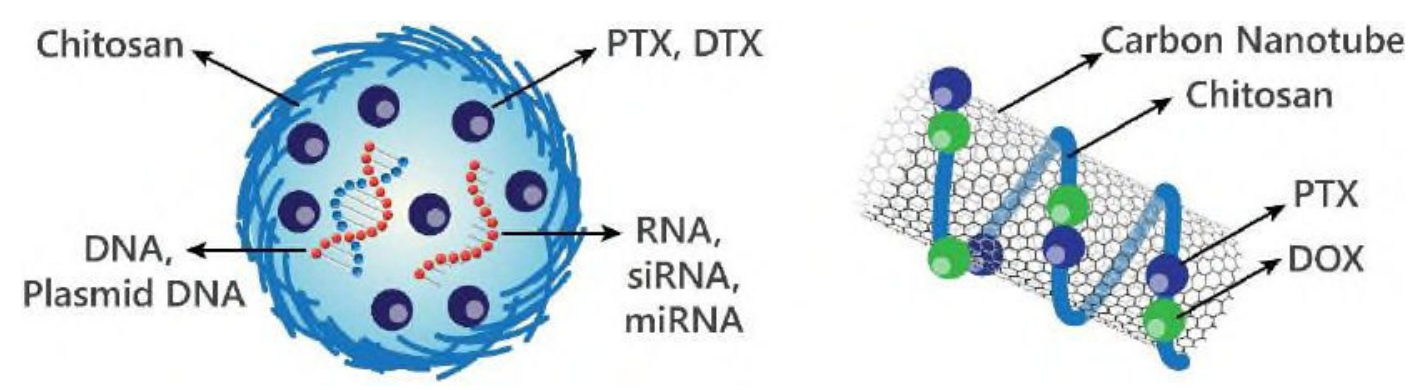

Figure 5: CNTs as potential candidates in the delivery of PTX and DTX.

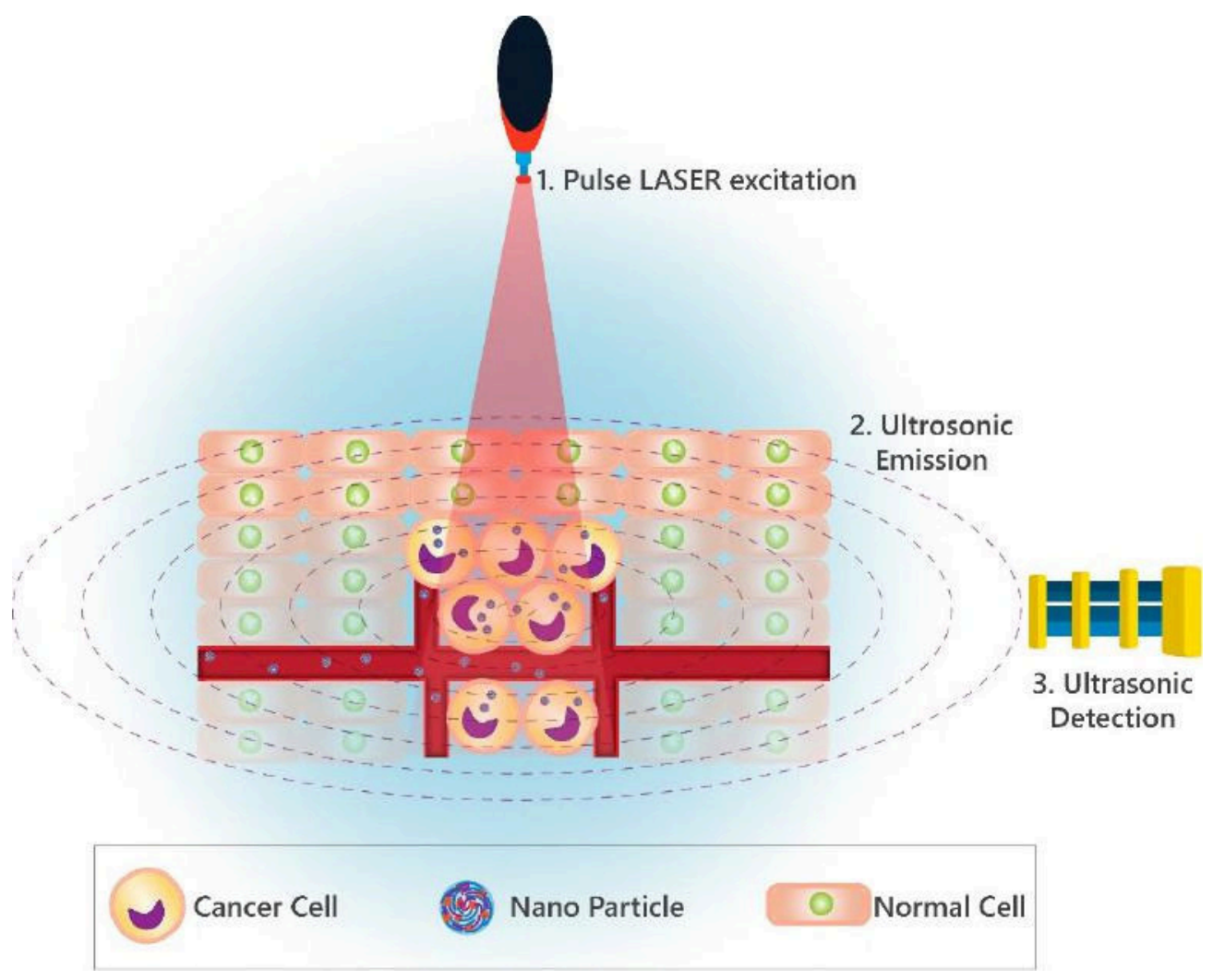

Figure 6: The application of CS-functionalized NPs in cancer imaging and theranostics. 


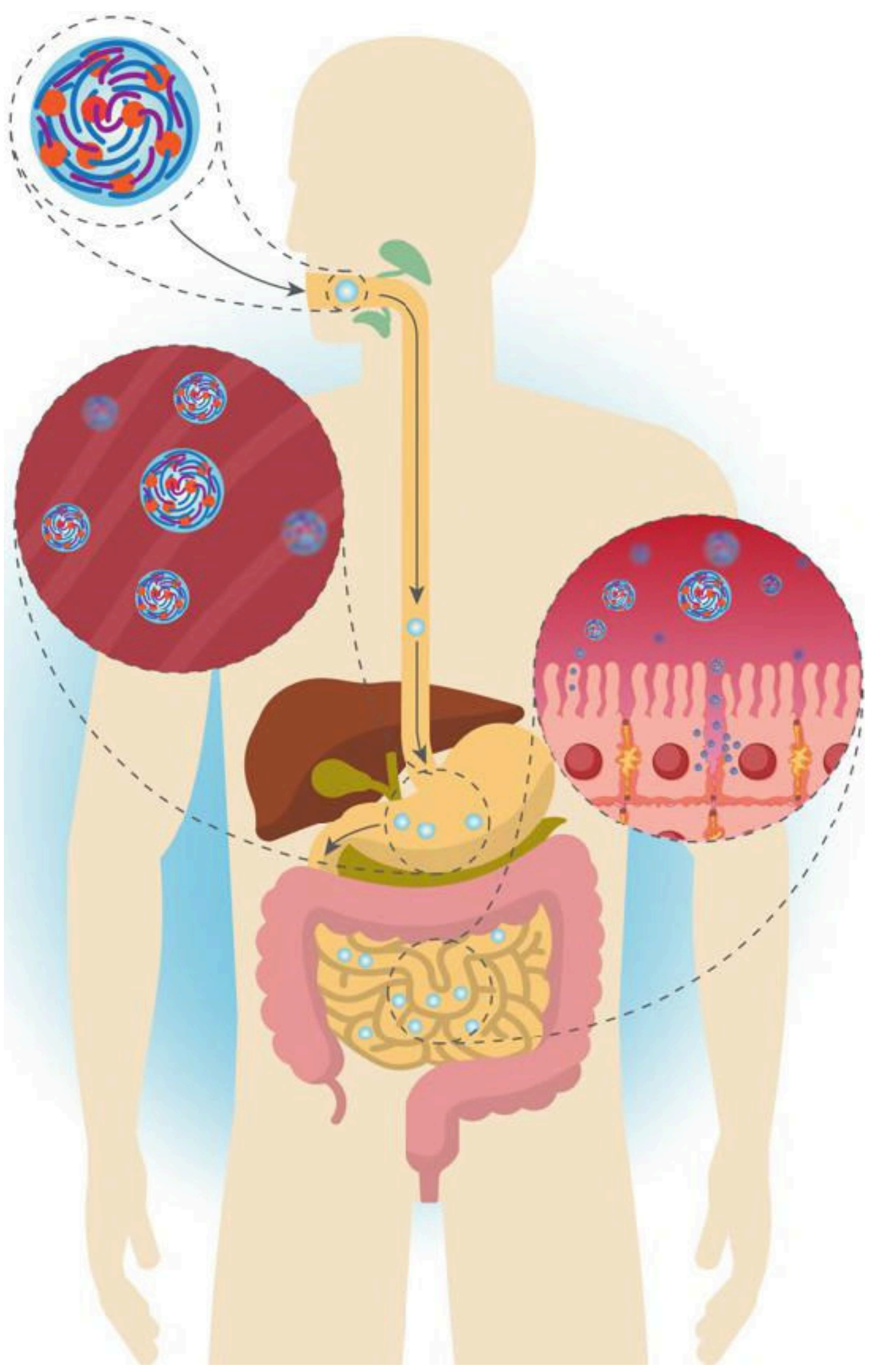

Figure 7: Protection against degradation in the stomach and enhancing the absorption of PTX and DTX through intestine by CS NPs. 


\section{References:}

[1] M. Doostmohammadi, A. Ameri, R. Mohammadinejad, N. Dehghannoudeh, I.M. Banat, M. Ohadi, G. Dehghannoudeh, Hydrogels For Peptide Hormones Delivery: Therapeutic And Tissue Engineering Applications, Drug Design, Development and Therapy 13 (2019) 3405-3418.

[2] F. Hassanzadeh Davarania, M. Ashrafizadeh, R. Saberi Riseh, Antifungal nanoparticles reduce aflatoxin contamination in pistachio, PHJ 1 (2018) 25-33.

[3] S. Tavakol, M. Ashrafizadeh, S. Deng, M. Azarian, A. Abdoli, M. Motavaf, D. Poormoghadam, H. Khanbabaei, E. Ghasemipour Afshar, A. Mandegary, Autophagy Modulators: Mechanistic Aspects and Drug Delivery Systems, Biomolecules 9(10) (2019) 530.

[4] G. Crini, Historical Landmarks in the Discovery of Chitin, in: G. Crini, E. Lichtfouse (Eds.), Sustainable Agriculture Reviews 35: Chitin and Chitosan: History, Fundamentals andInnovations, Springer International Publishing, Cham, 2019, pp. 1-47.

[5] W.J. Tang, Javier G. Fernandez, Joel J. Sohn, Chris T. Amemiya, Chitin Is Endogenously Produced in Vertebrates, Current Biology 25(7) (2015) 897-900.

[6] H.-Q. Mao, K. Roy, V.L. Troung-Le, K.A. Janes, K.Y. Lin, Y. Wang, J.T. August, K.W. Leong, Chitosan-DNA nanoparticles as gene carriers: synthesis, characterization and transfection efficiency, Journal of Controlled Release 70(3) (2001) 399-421.

[7] H.-j. Yen, Y.-a. Young, T.-n. Tsai, K.-m. Cheng, X.-a. Chen, Y.-c. Chen, C.-c. Chen, J.-j. Young, P.-d. Hong, Positively charged gold nanoparticles capped with folate quaternary chitosan: Synthesis, cytotoxicity, and uptake by cancer cells, Carbohydrate Polymers 183 (2018) 140-150.

[8] H. Tanuma, T. Saito, K. Nishikawa, T. Dong, K. Yazawa, Y. Inoue, Preparation and characterization of PEG-cross-linked chitosan hydrogel films with controllable swelling and enzymatic degradation behavior, Carbohydrate Polymers 80(1) (2010) 260-265.

[9] W. Mieszko, W.B. Klaus, G. Natalia, P.-S. Anna, Clinical Application of Chitosan in Dental Specialities, Mini-Reviews in Medicinal Chemistry 17(5) (2017) 401-409.

[10] S. Abasi, J.R. Aggas, A. Guiseppi-Elie, Physiochemical and morphological dependent growth of NIH/3T3 and PC-12 on polyaniline-chloride/chitosan bionanocomposites, Materials Science and Engineering: C 99 (2019) 1304-1312.

[11] M. Wieckiewicz, K. W Boening, N. Grychowska, A. Paradowska-Stolarz, Clinical application of chitosan in dental specialities, Mini reviews in medicinal chemistry 17(5) (2017) 401-409. 
[12] M. Mu, X. Li, A. Tong, G. Guo, Multi-functional chitosan-based smart hydrogels mediated biomedical application, Expert Opinion on Drug Delivery 16(3) (2019) 239-250.

[13] A.E. Nadimi, S.Y. Ebrahimipour, E.G. Afshar, S.K. Falahati-Pour, Z. Ahmadi, R.

Mohammadinejad, M. Mohamadi, Nano-scale drug delivery systems for antiarrhythmic agents, European journal of medicinal chemistry (2018).

[14] Y. Alinejad, A. Adoungotchodo, E. Hui, F. Zehtabi, S. Lerouge, An injectable chitosan/chondroitin sulfate hydrogel with tunable mechanical properties for cell therapy/tissue engineering, International Journal of Biological Macromolecules 113 (2018) 132-141.

[15] C. Intini, L. Elviri, J. Cabral, S. Mros, C. Bergonzi, A. Bianchera, L. Flammini, P. Govoni, E. Barocelli, R. Bettini, M. McConnell, 3D-printed chitosan-based scaffolds: An in vitro study of human skin cell growth and an in-vivo wound healing evaluation in experimental diabetes in rats, Carbohydrate Polymers 199 (2018) 593-602.

[16] S.A. Agnihotri, N.N. Mallikarjuna, T.M. Aminabhavi, Recent advances on chitosan-based microand nanoparticles in drug delivery, Journal of Controlled Release 100(1) (2004) 5-28.

[17] K. Nagpal, S.K. Singh, D.N. Mishra, Chitosan Nanoparticles: A Promising System in Novel Drug Delivery, Chemical and Pharmaceutical Bulletin 58(11) (2010) 1423-1430.

[18] Y. Ohya, M. Shiratani, H. Kobayashi, T. Ouchi, Release Behavior of 5-Fluorouracil from Chitosan-Gel Nanospheres Immobilizing 5-Fluorouracil Coated with Polysaccharides and Their Cell Specific Cytotoxicity, Journal of Macromolecular Science, Part A 31(5) (1994) 629-642.

[19] S. Rodrigues, A.M.R.d. Costa, A. Grenha, Chitosan/carrageenan nanoparticles: Effect of crosslinking with tripolyphosphate and charge ratios, Carbohydrate Polymers 89(1) (2012) 282-289.

[20] D.R. Bhumkar, V.B. Pokharkar, Studies on effect of $\mathrm{pH}$ on cross-linking of chitosan with sodium tripolyphosphate: A technical note, AAPS PharmSciTech 7(2) (2006) E138-E143.

[21] Q. Gan, T. Wang, C. Cochrane, P. McCarron, Modulation of surface charge, particle size and morphological properties of chitosan-TPP nanoparticles intended for gene delivery, Colloids and Surfaces B: Biointerfaces 44(2) (2005) 65-73.

[22] J. Ferlay, I. Soerjomataram, R. Dikshit, S. Eser, C. Mathers, M. Rebelo, D.M. Parkin, D. Forman, F. Bray, Cancer incidence and mortality worldwide: sources, methods and major patterns in GLOBOCAN 2012, International journal of cancer 136(5) (2015) E359-E386.

[23] P. Kesarwani, R.K. Tekade, N. Jain, Spectrophotometric estimation of paclitaxel, International Journal of Advances in Pharmaceutical Sciences 2(1) (2011). 
[24] K. Thanki, R.P. Gangwal, A.T. Sangamwar, S. Jain, Oral delivery of anticancer drugs: challenges and opportunities, Journal of controlled release 170(1) (2013) 15-40.

[25] L.A. Torre, F. Bray, R.L. Siegel, J. Ferlay, J. Lortet-Tieulent, A. Jemal, Global cancer statistics, 2012, CA: a cancer journal for clinicians 65(2) (2015) 87-108.

[26] P. Vineis, C.P. Wild, Global cancer patterns: causes and prevention, The Lancet 383(9916) (2014) 549-557.

[27] Z. Ahmadi, R. Mohammadinejad, M. Ashrafizadeh, Drug delivery systems for resveratrol, a nonflavonoid polyphenol: Emerging evidence in last decades, Journal of Drug Delivery Science and Technology (2019).

[28] National Center for Biotechnology Information. PubChem Database. Paclitaxel, CID=36314, https://pubchem.ncbi.nlm.nih.gov/compound/taxol (accessed on Dec. 5, 2019).

[29] National Center for Biotechnology Information. PubChem Database. Docetaxel, CID=148124, https://pubchem.ncbi.nlm.nih.gov/compound/Docetaxel (accessed on Dec. 5, 2019).

[30] M. Ashrafizadeh, Z. Ahmadi, N.G. Kotla, E.G. Afshar, S. Samarghandian, A. Mandegary, A. Pardakhty, R. Mohammadinejad, G. Sethi, Nanoparticles Targeting STATs in Cancer Therapy, Cells 8(10) (2019) 1158.

[31] A. Dehshahri, M. Ashrafizadeh, E.G. Afshar, A. Pardakhty, A. Mandegary, R. Mohammadinejad, G. Sethi, Topoisomerase inhibitors: pharmacology and emerging nanoscale delivery systems, Pharmacological Research 151 (2020) 104551.

[32] R.C. Alves, R.P. Fernandes, J.O. Eloy, H.R.N. Salgado, M. Chorilli, Characteristics, properties and analytical methods of paclitaxel: a review, Critical reviews in analytical chemistry 48(2) (2018) $110-118$.

[33] S. Guo, Y. Zhang, Z. Wu, L. Zhang, D. He, X. Li, Z. Wang, Synergistic combination therapy of lung cancer: Cetuximab functionalized nanostructured lipid carriers for the co-delivery of paclitaxel and 5-Demethylnobiletin, Biomedicine \& Pharmacotherapy 118 (2019) 109225.

[34] M. Raab, N.F. Kobayashi, S. Becker, E. Kurunci-Csacsko, A. Krämer, K. Strebhardt, M. Sanhaji, Boosting the apoptotic response of high grade serous ovarian cancers with CCNE1-amplification to paclitaxel in vitro by targeting APC/C and the pro-survival protein MCL-1, International journal of cancer (2019).

[35] S. Shi, W. Fu, S. Lin, T. Tian, S. Li, X. Shao, Y. Zhang, T. Zhang, Z. Tang, Y. Zhou, Targeted and effective glioblastoma therapy via aptamer-modified tetrahedral framework nucleic acid-paclitaxel 
Nanoconjugates that can pass the blood brain barrier, Nanomedicine: Nanotechnology, Biology and Medicine (2019) 102061.

[36] J.J. Liu, J.Y. Ho, H.W. Lee, M.W. Baik, O. Kim, Y.J. Choi, S.Y. Hur, Inhibition of Phosphatidylinositol 3-kinase (PI3K) Signaling Synergistically Potentiates Antitumor Efficacy of Paclitaxel and Overcomes Paclitaxel-Mediated Resistance in Cervical Cancer, International journal of molecular sciences 20(14) (2019) 3383.

[37] Y. Wang, J. Wang, L. Yang, W. Wei, B. Sun, K. Na, Y. Song, H. Zhang, Z. He, J. Sun, Redox dual-responsive paclitaxel-doxorubicin heterodimeric prodrug self-delivery nanoaggregates for more effective breast cancer synergistic combination chemotherapy, Nanomedicine: Nanotechnology, Biology and Medicine (2019) 102066.

[38] H. Soltani-Sedeh, S. Irani, R. Mirfakhraie, M. Soleimani, Potential using of microRNA-34A in combination with paclitaxel in colorectal cancer cells, Journal of cancer research and therapeutics 15(1) (2019) 32.

[39] E.K. Rowinsky, R.C. Donehower, Paclitaxel (taxol), New England journal of medicine 332(15) (1995) 1004-1014.

[40] W.P. McGuire, E.K. Rowinsky, N.B. Rosenshein, F.C. Grumbine, D.S. Ettinger, D.K. Armstrong, R.C. Donehower, Taxol: a unique antineoplastic agent with significant activity in advanced ovarian epithelial neoplasms, Annals of internal medicine 111(4) (1989) 273-279.

[41] T. Tan, B. Stevenson, D. Yip, Docetaxel-induced nasal septal perforation, Internal medicine journal 36(7) (2006) 471-472.

[42] M.A. Jordan, L. Wilson, Microtubules as a target for anticancer drugs, Nature Reviews Cancer 4(4) (2004) 253.

[43] M. Magnani, G. Maccari, J.M. Andreu, J. Diaz, M. Botta, Possible binding site for paclitaxel at microtubule pores, The FEBS journal 276(10) (2009) 2701-2712.

[44] P. Marchetti, S.k. Urien, G.A. Cappellini, G. Ronzino, C. Ficorella, Weekly administration of paclitaxel: theoretical and clinical basis, Critical reviews in oncology/hematology 44 (2002) 3-13.

[45] F. Mollinedo, C. Gajate, Microtubules, microtubule-interfering agents and apoptosis, Apoptosis $8(5)(2003)$ 413-450.

[46] M.X. Lee, D.S. Tan, Weekly versus 3-weekly paclitaxel in combination with carboplatin in advanced ovarian cancer: which is the optimal adjuvant chemotherapy regimen?, Journal of gynecologic oncology 29(6) (2018). 
[47] G.H. da Silva, M.A. Fernandes, L.N.F. Trevizan, F.T. de Lima, J.O. Eloy, M. Chorilli, A critical review of properties and analytical methods for the determination of docetaxel in biological and pharmaceutical matrices, Critical reviews in analytical chemistry 48(6) (2018) 517-527.

[48] N.B. Andriguetti, S. Raymundo, M.V. Antunes, M.S. Perassolo, S.G. Verza, E.S. Suyenaga, R. Linden, Pharmacogenetic and pharmacokinetic dose individualization of the taxane chemotherapeutic drugs paclitaxel and docetaxel, Current medicinal chemistry 24(33) (2017) 3559-3582.

[49] J. Puente, E. Grande, A. Medina, P. Maroto, N. Lainez, J.A. Arranz, Docetaxel in prostate cancer: a familiar face as the new standard in a hormone-sensitive setting, Therapeutic advances in medical oncology 9(5) (2017) 307-318.

[50] N. Summers, J. Vanderpuye-Orgle, M. Reinhart, M. Gallagher, O. Sartor, Efficacy and safety of post-docetaxel therapies in metastatic castration-resistant prostate cancer: a systematic review of the literature, Current medical research and opinion 33(11) (2017) 1995-2008.

[51] M.F. Sohail, M. Rehman, H.S. Sarwar, S. Naveed, O. Salman, N.I. Bukhari, I. Hussain, T.J. Webster, G. Shahnaz, Advancements in the oral delivery of Docetaxel: Challenges, current state-ofthe-art and future trends, International journal of nanomedicine 13 (2018) 3145.

[52] K. Uoto, I. Mitsui, H. Terasawa, T. Soga, First synthesis and cytotoxic activity of novel docetaxel analogs modified at the C18-position, Bioorganic \& Medicinal Chemistry Letters 7(23) (1997) 29912996.

[53] A.-M.C. Yvon, P. Wadsworth, M.A. Jordan, Taxol suppresses dynamics of individual microtubules in living human tumor cells, Molecular biology of the cell 10(4) (1999) 947-959.

[54] S.G. Arbuck, B.A. Blaylock, Taxol: clinical results and current issues in development, Taxol: Science and Applications 379 (1995).

[55] B.M. Rao, A. Chakraborty, M. Srinivasu, M.L. Devi, P.R. Kumar, K. Chandrasekhar, A. Srinivasan, A. Prasad, J. Ramanatham, A stability-indicating HPLC assay method for docetaxel, Journal of pharmaceutical and biomedical analysis 41(2) (2006) 676-681.

[56] G.R. Valicherla, K.M. Dave, A.A. Syed, M. Riyazuddin, A.P. Gupta, A. Singh, K. Mitra, D. Datta, J.R. Gayen, Formulation optimization of Docetaxel loaded self-emulsifying drug delivery system to enhance bioavailability and anti-tumor activity, Scientific reports 6 (2016) 26895.

[57] S.-S. Feng, L. Zhao, Z. Zhang, G. Bhakta, K.Y. Win, Y. Dong, S. Chien, Chemotherapeutic engineering: vitamin E TPGS-emulsified nanoparticles of biodegradable polymers realized sustainable paclitaxel chemotherapy for $168 \mathrm{~h}$ in vivo, Chemical Engineering Science 62(23) (2007) 6641-6648. 
[58] M. Ashrafizadeh, Z. Ahmadi, R. Mohamamdinejad, T. Farkhondeh, S. Samarghandian, Curcumin Activates the Nrf2 Pathway and Induces Cellular Protection Against Oxidative Injury, Current Molecular Medicine (2020).

[59] M. Ashrafizadeh, Z. Ahmadi, R. Mohammadinejad, T. Farkhondeh, S. Samarghandian, Nanosoldiers ameliorate silibinin delivery: A review study, Current Drug Delivery (2019).

[60] V. Zabaleta, G. Ponchel, H. Salman, M. Agüeros, C. Vauthier, J.M. Irache, Oral administration of paclitaxel with pegylated poly (anhydride) nanoparticles: permeability and pharmacokinetic study, European Journal of Pharmaceutics and Biopharmaceutics 81(3) (2012) 514-523.

[61] J.-S. Choi, N.H. Cho, D.-H. Kim, J.-S. Park, Comparison of paclitaxel solid dispersion and polymeric micelles for improved oral bioavailability and in vitro anti-cancer effects, Materials Science and Engineering: C 100 (2019) 247-259.

[62] C.M. Jackson, J. Choi, M. Lim, Mechanisms of immunotherapy resistance: lessons from glioblastoma, Nature immunology (2019).

[63] P.K. Singh, A.K. Srivastava, A. Dev, B. Kaundal, S.R. Choudhury, S. Karmakar, 1, 3ß-Glucan anchored, paclitaxel loaded chitosan nanocarrier endows enhanced hemocompatibility with efficient anti-glioblastoma stem cells therapy, Carbohydrate polymers 180 (2018) 365-375.

[64] A.K. Singla, A. Garg, D. Aggarwal, Paclitaxel and its formulations, International journal of pharmaceutics 235(1-2) (2002) 179-192.

[65] W.J. Trickler, D.J. Munt, N. Jain, S.S. Joshi, A.K. Dash, Antitumor efficacy, tumor distribution and blood pharmacokinetics of chitosan/glyceryl-monooleate nanostructures containing paclitaxel, Nanomedicine 6(3) (2011) 437-448.

[66] J. Xu, L. Ma, Y. Liu, F. Xu, J. Nie, G. Ma, Design and characterization of antitumor drug paclitaxel-loaded chitosan nanoparticles by W/O emulsions, International journal of biological macromolecules 50(2) (2012) 438-443.

[67] J. Jiang, Y. Liu, C. Wu, Y. Qiu, X. Xu, H. Lv, A. Bai, X. Liu, Development of drug-loaded chitosan hollow nanoparticles for delivery of paclitaxel to human lung cancer A549 cells, Drug development and industrial pharmacy 43(8) (2017) 1304-1313.

[68] S.P. Akhlaghi, S. Saremi, S.N. Ostad, R. Dinarvand, F. Atyabi, Discriminated effects of thiolated chitosan-coated pMMA paclitaxel-loaded nanoparticles on different normal and cancer cell lines, Nanomedicine: Nanotechnology, Biology and Medicine 6(5) (2010) 689-697. 
[69] X.-Y. Chu, W. Huang, Y.-L. Wang, L.-W. Meng, L.-Q. Chen, M.-J. Jin, L. Chen, C.-H. Gao, C. Ge, Z.-G. Gao, Improving antitumor outcomes for palliative intratumoral injection therapy through lecithin- chitosan nanoparticles loading paclitaxel-cholesterol complex, International journal of nanomedicine 14 (2019) 689.

[70] U. Gupta, S. Sharma, I. Khan, A. Gothwal, A.K. Sharma, Y. Singh, M.K. Chourasia, V. Kumar, Enhanced apoptotic and anticancer potential of paclitaxel loaded biodegradable nanoparticles based on chitosan, International journal of biological macromolecules 98 (2017) 810-819.

[71] K.H. Min, K. Park, Y.-S. Kim, S.M. Bae, S. Lee, H.G. Jo, R.-W. Park, I.-S. Kim, S.Y. Jeong, K. Kim, Hydrophobically modified glycol chitosan nanoparticles-encapsulated camptothecin enhance the drug stability and tumor targeting in cancer therapy, Journal of Controlled Release 127(3) (2008) 208218.

[72] M.A. Razi, R. Wakabayashi, M. Goto, N. Kamiya, Self-assembled reduced albumin and glycol chitosan nanoparticles for paclitaxel delivery, Langmuir 35(7) (2019) 2610-2618.

[73] R.-F. Song, X.-J. Li, X.-L. Cheng, A.-R. Fu, Y.-H. Wang, Y.-J. Feng, Y. Xiong, Paclitaxelloaded trimethyl chitosan-based polymeric nanoparticle for the effective treatment of gastroenteric tumors, Oncology reports 32(4) (2014) 1481-1488.

[74] W. Trickler, A. Nagvekar, A.K. Dash, The in vitro sub-cellular localization and in vivo efficacy of novel chitosan/GMO nanostructures containing paclitaxel, Pharmaceutical research 26(8) (2009) 1963-1973.

[75] Y.-J. Ye, Y. Wang, K.-Y. Lou, Y.-Z. Chen, R. Chen, F. Gao, The preparation, characterization, and pharmacokinetic studies of chitosan nanoparticles loaded with paclitaxel/dimethyl- $\beta$-cyclodextrin inclusion complexes, International journal of nanomedicine 10 (2015) 4309.

[76] H. Zhou, X. Liu, X. Guo, N. Li, W. Yu, Y. Zhang, X. Ma, Synthesis and characterization of amphiphilic chitosan derivatives as a nano-carrier for paclitaxel delivery, Journal Of Controlled Release 152 (2011).

[77] G. Battogtokh, Y.T. Ko, Self-assembled polymeric nanoparticle of PEGylated chitosan-ceramide conjugate for systemic delivery of paclitaxel, Journal of drug targeting 22(9) (2014) 813-821.

[78] Y.-s. Wang, Q. Jiang, R.-s. Li, L.-1. Liu, Q.-q. Zhang, Y.-m. Wang, J. Zhao, Self-assembled nanoparticles of cholesterol-modified O-carboxymethyl chitosan as a novel carrier for paclitaxel, Nanotechnology 19(14) (2008) 145101.

[79] J. Yu, Y. Liu, L. Zhang, J. Zhao, J. Ren, L. Zhang, Y. Jin, Self-aggregated nanoparticles of linoleic acid-modified glycol chitosan conjugate as delivery vehicles for paclitaxel: Preparation, 
characterization and evaluation, Journal of Biomaterials Science, Polymer Edition 26(18) (2015) 1475-1489.

[80] F. Bray, J. Ferlay, I. Soerjomataram, R.L. Siegel, L.A. Torre, A. Jemal, Global cancer statistics 2018: GLOBOCAN estimates of incidence and mortality worldwide for 36 cancers in 185 countries, CA: a cancer journal for clinicians 68(6) (2018) 394-424.

[81] S. Zheng, M. Li, K. Miao, H. Xu, SNHG1 contributes to proliferation and invasion by regulating miR-382 in breast cancer, Cancer Management and Research 11 (2019) 5589.

[82] P. Gotwals, S. Cameron, D. Cipolletta, V. Cremasco, A. Crystal, B. Hewes, B. Mueller, S. Quaratino, C. Sabatos-Peyton, L. Petruzzelli, Prospects for combining targeted and conventional cancer therapy with immunotherapy, Nature Reviews Cancer 17(5) (2017) 286.

[83] S. Nagini, Breast cancer: current molecular therapeutic targets and new players, Anti-Cancer Agents in Medicinal Chemistry (Formerly Current Medicinal Chemistry-Anti-Cancer Agents) 17(2) (2017) 152163.

[84] A. Jain, K. Thakur, P. Kush, U.K. Jain, Docetaxel loaded chitosan nanoparticles: formulation, characterization and cytotoxicity studies, International journal of biological macromolecules 69 (2014) 546-553.

[85] Z.H. Mirzaie, S. Irani, R. Mirfakhraie, S.M. Atyabi, M. Dinarvand, R. Dinarvand, R. Varshochian, F. Atyabi, Docetaxel-Chitosan nanoparticles for breast cancer treatment: cell viability and gene expression study, Chemical biology \& drug design 88(6) (2016) 850-858.

[86] P. Favoriti, G. Carbone, M. Greco, F. Pirozzi, R.E.M. Pirozzi, F. Corcione, Worldwide burden of colorectal cancer: a review, Updates in surgery 68(1) (2016) 7-11.

[87] A. Shaukat, A. Dostal, J. Menk, T.R. Church, BMI is a risk factor for colorectal cancer mortality, Digestive diseases and sciences 62(9) (2017) 2511-2517.

[88] M.M. Badran, A.H. Alomrani, G.I. Harisa, A.E. Ashour, A. Kumar, A.E. Yassin, Novel docetaxel chitosan-coated PLGA/PCL nanoparticles with magnified cytotoxicity and bioavailability, Biomedicine \& Pharmacotherapy 106 (2018) 1461-1468.

[89] C.K. Balavigneswaran, S.K. Mahto, B. Subia, A. Prabhakar, K. Mitra, V. Rao, M. Ganguli, B. Ray, P. Maiti, N. Misra, Tailored chemical properties of 4-arm star shaped poly (D, L-lactide) as cell adhesive three-dimensional scaffolds, Bioconjugate chemistry 28(4) (2017) 1236-1250.

[90] S. Mazzaferro, K. Bouchemal, R. Skanji, C. Gueutin, H. Chacun, G. Ponchel, Intestinal permeation enhancement of docetaxel encapsulated into methyl- $\beta$-cyclodextrin/poly 
(isobutylcyanoacrylate) nanoparticles coated with thiolated chitosan, Journal of controlled release 162(3) (2012) 568-574.

[91] M. Hatamipour, A. Sahebkar, S.H. Alavizadeh, M. Dorri, M.R. Jaafari, Novel nanomicelle formulation to enhance bioavailability and stability of curcuminoids, Iranian journal of basic medical sciences 22(3) (2019) 282.

[92] T. Trimaille, B. Verrier, Micelle-based adjuvants for subunit vaccine delivery, Vaccines 3(4) (2015) 803-813.

[93] M. Mobasheri, H. Attar, S. Rezayat Sorkhabadi, A. Khamesipour, M. Jaafari, Solubilization behavior of polyene antibiotics in nanomicellar system: Insights from molecular dynamics simulation of the amphotericin B and nystatin interactions with polysorbate 80, Molecules 21(1) (2016) 6.

[94] A. Shakeri, A. Sahebkar, Opinion Paper: Nanotechnology: A Successful Approach to Improve Oral Bioavailability of Phytochemicals, Recent patents on drug delivery \& formulation 10(1) (2016) 4-6.

[95] Z. Pan, Y. Gao, L. Heng, Y. Liu, G. Yao, Y. Wang, Y. Liu, Amphiphilic N-(2, 3dihydroxypropyl)- chitosan-cholic acid micelles for paclitaxel delivery, Carbohydrate polymers 94(1) (2013) 394-399.

[96] J. Liu, H. Li, D. Chen, X. Jin, X. Zhao, C. Zhang, Q. Ping, In vivo evaluation of novel chitosan graft polymeric micelles for delivery of paclitaxel, Drug delivery 18(3) (2011) 181-189.

[97] N. Liang, S. Sun, J. Hong, J. Tian, L. Fang, F. Cui, In vivo pharmacokinetics, biodistribution and antitumor effect of paclitaxel-loaded micelles based on $\alpha$-tocopherol succinate-modified chitosan, Drug delivery 23(8) (2016) 2651-2660.

[98] X. Jin, R. Mo, Y. Ding, W. Zheng, C. Zhang, Paclitaxel-loaded N-octyl-O-sulfate chitosan micelles for superior cancer therapeutic efficacy and overcoming drug resistance, Molecular pharmaceutics 11(1) (2013) 145-157.

[99] S. Mollazadeh, A. Sahebkar, F. Hadizadeh, J. Behravan, S. Arabzadeh, Structural and functional aspects of P-glycoprotein and its inhibitors, Life sciences (2018).

[100]G. Qu, Z. Yao, C. Zhang, X. Wu, Q. Ping, PEG conjugated N-octyl-O-sulfate chitosan micelles for delivery of paclitaxel: in vitro characterization and in vivo evaluation, European Journal of Pharmaceutical Sciences 37(2) (2009) 98-105. 
[101]A. Almeida, D. Silva, V. Gonçalves, B. Sarmento, Synthesis and characterization of chitosangrafted-polycaprolactone micelles for modulate intestinal paclitaxel delivery, Drug delivery and translational research 8(2) (2018) 387-397.

[102]Y. Chen, S. Feng, W. Liu, Z. Yuan, P. Yin, F. Gao, Vitamin E succinate-grafted-chitosan oligosaccharide/RGD-conjugated TPGS mixed micelles loaded with paclitaxel for U87MG tumor therapy, Molecular pharmaceutics 14(4) (2017) 1190-1203.

[0] F.-Q. Hu, G.-F. Ren, H. Yuan, Y.-Z. Du, S. Zeng, Shell cross-linked stearic acid grafted chitosan oligosaccharide self-aggregated micelles for controlled release of paclitaxel, Colloids and Surfaces B: Biointerfaces 50(2) (2006) 97-103.

[1] M. Huo, J. Zhou, Y. Wei, L. Lü, Preparation of paclitaxel-loaded chitosan polymeric micelles and influence of surface charges on their tissue biodistribution in mice, Yao xue xue bao= Acta pharmaceutica Sinica 41(9) (2006) 867-872.

[2] H. Lian, J. Sun, Y.P. Yu, Y.H. Liu, W. Cao, Y.J. Wang, Y.H. Sun, S.L. Wang, Z.G. He, Supramolecular micellar nanoaggregates based on a novel chitosan/vitamin E succinate copolymer for paclitaxel selective delivery, International journal of nanomedicine 6 (2011) 3323.

[106] N. Liang, S. Sun, X. Gong, Q. Li, P. Yan, F. Cui, Polymeric micelles based on modified glycol chitosan for paclitaxel delivery: Preparation, characterization and evaluation, International journal of molecular sciences 19(6) (2018) 1550.

[107] N. Liang, S. Sun, X. Li, H. Piao, H. Piao, F. Cui, L. Fang, $\alpha$-Tocopherol succinate-modified chitosan as a micellar delivery system for paclitaxel: Preparation, characterization and in vitro/in vivo evaluations, International journal of pharmaceutics 423(2) (2012) 480-488.

[108] Z.-q. Yuan, J.-z. Li, Y. Liu, W.-1. Chen, C.-g. Zhang, W.-j. Zhu, X.-f. Zhou, C. Liu, X.-n. Zhang, Systemic delivery of micelles loading with paclitaxel using N-succinyl-palmitoyl-chitosan decorated with cRGDyK peptide to inhibit non-small-cell lung cancer, International journal of pharmaceutics 492(1-2) (2015) 141-151.

[109] C. Zhang, P. Qineng, H. Zhang, Self-assembly and characterization of paclitaxel-loaded Noctyl-O-sulfate chitosan micellar system, Colloids and Surfaces B: Biointerfaces 39(1-2) (2004) 6975.

[110] C. Zhang, G. Qu, Y. Sun, X. Wu, Z. Yao, Q. Guo, Q. Ding, S. Yuan, Z. Shen, Q. Ping, Pharmacokinetics, biodistribution, efficacy and safety of N-octyl-O-sulfate chitosan micelles loaded with paclitaxel, Biomaterials 29(9) (2008) 1233-1241.

[111] J.V. Andhariya, D.J. Burgess, Recent advances in testing of microsphere drug delivery systems, Expert opinion on drug delivery 13(4) (2016) 593-608. 
[112] M.M. Pour, R. Saberi-Riseh, R. Mohammadinejad, A. Hosseini, Investigating the formulation of alginate-gelatin encapsulated Pseudomonas fluorescens (VUPF5 and T17-4 strains) for controlling Fusarium solani on potato, International Journal of Biological Macromolecules 133 (2019) 603-613.

[113] M.M. Pour, R. Saberi-Riseh, R. Mohammadinejad, A. Hosseini, Nano-Encapsulation of Plant Growth-Promoting Rhizobacteria and Their Metabolites Using Alginate-Silica Nanoparticles and Carbon Nanotube Improves UCB1 Pistachio Micropropagation, Journal of Microbiology and Biotechnology 29(7) (2019) 1096-1103.

[114] M. Shameem, H. Lee, P.P. DeLuca, A short-term (accelerated release) approach to evaluate peptide release from PLGA depot formulations, AAPS PharmSci 1(3) (1999) 1.

[115] T.G. Park, W. Lu, G. Crotts, Importance of in vitro experimental conditions on protein release kinetics, stability and polymer degradation in protein encapsulated poly (D, L-lactic acid-co-glycolic acid) microspheres, Journal of Controlled Release 33(2) (1995) 211-222.

[116] J. Shen, D.J. Burgess, Accelerated in-vitro release testing methods for extended-release parenteral dosage forms, Journal of Pharmacy and Pharmacology 64(7) (2012) 986-996.

[117] U. Edlund, A.-C. Albertsson, Degradable polymer microspheres for controlled drug delivery, Degradable aliphatic polyesters, Springer2002, pp. 67-112.

[118] B.S. Zolnik, D.J. Burgess, Evaluation of in vivo-in vitro release of dexamethasone from PLGA microspheres, Journal of controlled release 127(2) (2008) 137-145.

[119] H. Wang, Y. Xu, X. Zhou, Docetaxel-loaded chitosan microspheres as a lung targeted drug delivery system: in vitro and in vivo evaluation, International journal of molecular sciences 15(3) (2014) 35193532.

[120] R. Yang, S.-G. Yang, W.-S. Shim, F. Cui, G. Cheng, I.-W. Kim, D.-D. Kim, S.-J. Chung, C.-K. Shim, Lung-specific delivery of paclitaxel by chitosan-modified PLGA nanoparticles via transient formation of microaggregates, Journal of pharmaceutical sciences 98(3) (2009) 970-984.

[121] N.A. Peppas, J.Z. Hilt, A. Khademhosseini, R. Langer, Hydrogels in biology and medicine: from molecular principles to bionanotechnology, Advanced materials 18(11) (2006) 1345-1360.

[122] B.V. Slaughter, S.S. Khurshid, O.Z. Fisher, A. Khademhosseini, N.A. Peppas, Hydrogels in regenerative medicine, Advanced materials 21(32-33) (2009) 3307-3329.

[123] A.S. Hoffman, Hydrogels for biomedical applications, Advanced drug delivery reviews 64 (2012) 1823. 
[124] R. Mohammadinejad, H. Maleki, E. Larrañeta, A.R. Fajardo, A.B. Nik, A. Shavandi, A. Sheikhi, M. Ghorbanpour, M. Farokhi, P. Govindh, Status and future scope of plant-based green hydrogels in biomedical engineering, Applied Materials Today 16 (2019) 213-246.

[125] S. Azizi, R. Mohamad, R.A. Rahim, R. Mohammadinejad, A.B. Ariff, Hydrogel beads bionanocomposite based on Kappa-Carrageenan and green synthesized silver nanoparticles for biomedical applications, International journal of biological macromolecules 104 (2017) 423-431.

[126] K. Obara, M. Ishihara, Y. Ozeki, T. Ishizuka, T. Hayashi, S. Nakamura, Y. Saito, H. Yura, T. Matsui, H. Hattori, Controlled release of paclitaxel from photocrosslinked chitosan hydrogels and its subsequent effect on subcutaneous tumor growth in mice, Journal of controlled release 110(1) (2005) 79-89.

[127] M. Ishihara, M. Fujita, K. Obara, H. Hattori, S. Nakamura, M. Nambu, T. Kiyosawa, Y. Kanatani, B. Takase, M. Kikuchi, Controlled releases of FGF-2 and paclitaxel from chitosan hydrogels and their subsequent effects on wound repair, angiogenesis, and tumor growth, Current drug delivery 3(4) (2006) 351-358.

[128] N. Zhang, X. Xu, X. Zhang, D. Qu, L. Xue, R. Mo, C. Zhang, Nanocomposite hydrogel incorporating gold nanorods and paclitaxel-loaded chitosan micelles for combination photothermalchemotherapy, International journal of pharmaceutics 497(1-2) (2016) 210-221.

[129] S.A. Abouelmagd, Y.J. Ku, Y. Yeo, Low molecular weight chitosan-coated polymeric nanoparticles for sustained and $\mathrm{pH}$-sensitive delivery of paclitaxel, Journal of drug targeting 23(7-8) (2015) 725-735.

[130] L.E. Gerweck, K. Seetharaman, Cellular $\mathrm{pH}$ gradient in tumor versus normal tissue: potential exploitation for the treatment of cancer, Cancer Research 56(6) (1996) 1194-1198.

[131] M. Stubbs, P.M. McSheehy, J.R. Griffiths, C.L. Bashford, Causes and consequences of tumour acidity and implications for treatment, Molecular medicine today 6(1) (2000) 15-19.

[132] H. Li, J. Liu, S. Ding, C. Zhang, W. Shen, Q. You, Synthesis of novel pH-sensitive chitosan graft copolymers and micellar solubilization of paclitaxel, International journal of biological macromolecules 44(3) (2009) 249-256.

[133] Y. Zhang, W. Zhu, H. Zhang, J. Han, L. Zhang, Q. Lin, F. Ai, Carboxymethyl chitosan/phospholipid bilayer-capped mesoporous carbon nanoparticles with $\mathrm{pH}$-responsive and prolonged release properties for oral delivery of the antitumor drug, Docetaxel, International journal of pharmaceutics 532(1) (2017) 384-392.

[134] J.I. Pesoa, M.J. Rico, V.R. Rozados, O.G. Scharovsky, J.A. Luna, L.N. Mengatto, Paclitaxel delivery system based on poly(lactide-co-glycolide) microparticles and chitosan thermo-sensitive gel 
for mammary adenocarcinoma treatment, Journal of Pharmacy and Pharmacology 70(11) (2018) 14941502.

[135] C. Chun, S.M. Lee, S.Y. Kim, H.K. Yang, S.-C. Song, Thermosensitive poly (organophosphazene)- paclitaxel conjugate gels for antitumor applications, Biomaterials 30(12) (2009) 2349-2360.

[136] C. Li, S. Ren, Y. Dai, F. Tian, X. Wang, S. Zhou, S. Deng, Q. Liu, J. Zhao, X. Chen, Efficacy, pharmacokinetics, and biodistribution of thermosensitive chitosan/ $\beta$-glycerophosphate hydrogel loaded with docetaxel, AAPS PharmSciTech 15(2) (2014) 417-424.

[137] Y. Wang, H. Xu, J. Wang, L. Ge, J. Zhu, Development of a thermally responsive nanogel based on chitosan-poly (N-isopropylacrylamide-co-acrylamide) for paclitaxel delivery, Journal of pharmaceutical sciences 103(7) (2014) 2012-2021.

[138] E. Ruel-Gariépy, M. Shive, A. Bichara, M. Berrada, D. Le Garrec, A. Chenite, J.-C. Leroux, A thermosensitive chitosan-based hydrogel for the local delivery of paclitaxel, European Journal of Pharmaceutics and Biopharmaceutics 57(1) (2004) 53-63.

[139] J. Xuan, D. Han, H. Xia, Y. Zhao, Dual-stimuli-responsive micelle of an ABC triblock copolymer bearing a redox-cleavable unit and a photocleavable unit at two block junctions, Langmuir 30(1) (2013) 410-417.

[140] L. Chen, F. Chen, M. Zhao, X. Zhu, C. Ke, J. Yu, Z. Yan, F. Zhang, Y. Sun, D. Chen, A redoxsensitive micelle-like nanoparticle self-assembled from amphiphilic adriamycin-human serum albumin conjugates for tumor targeted therapy, BioMed research international 2015 (2015).

[141] Y. Lv, B. Yang, Y.-M. Li, Y. Wu, F. He, R.-X. Zhuo, Crosslinked triblock copolymeric micelle for redox-responsive drug delivery, Colloids and Surfaces B: Biointerfaces 122 (2014) 223-230.

[142] M. Huo, Y. Liu, L. Wang, T. Yin, C. Qin, Y. Xiao, L. Yin, J. Liu, J. Zhou, Redox-sensitive micelles based on $\mathrm{O}$, N-hydroxyethyl chitosan-octylamine conjugates for triggered intracellular delivery of paclitaxel, Molecular pharmaceutics 13(6) (2016) 1750-1762.

[143] B. Khorsand, G. Lapointe, C. Brett, J.K. Oh, Intracellular drug delivery nanocarriers of glutathione-responsive degradable block copolymers having pendant disulfide linkages,

Biomacromolecules 14(6) (2013) 2103-2111.

[144] N.L. Dhas, P.P. Ige, R.R. Kudarha, Design, optimization and in-vitro study of folic acid conjugated-chitosan functionalized PLGA nanoparticle for delivery of bicalutamide in prostate cancer, Powder technology 283 (2015) 234-245. 
[145] A. Scomparin, S. Salmaso, A. Eldar-Boock, D. Ben-Shushan, S. Ferber, G. Tiram, H. Shmeeda, N. Landa-Rouben, J. Leor, P. Caliceti, A comparative study of folate receptor-targeted doxorubicin delivery systems: dosing regimens and therapeutic index, Journal of controlled release 208 (2015) 106-120.

[146] L. Li, N. Liang, D. Wang, P. Yan, Y. Kawashima, F. Cui, S. Sun, Amphiphilic Polymeric Micelles Based on Deoxycholic Acid and Folic Acid Modified Chitosan for the Delivery of Paclitaxel, International journal of molecular sciences 19(10) (2018) 3132.

[147] F. Wang, Y. Chen, D. Zhang, Q. Zhang, D. Zheng, L. Hao, Y. Liu, C. Duan, L. Jia, G. Liu, Folate-mediated targeted and intracellular delivery of paclitaxel using a novel deoxycholic acid-Ocarboxymethylated chitosan-folic acid micelles, International journal of nanomedicine 7 (2012) 325 .

[148] L.-C. Cheng, Y. Jiang, Y. Xie, L.-L. Qiu, Q. Yang, H.-Y. Lu, Novel amphiphilic folic acidcholesterol-chitosan micelles for paclitaxel delivery, Oncotarget 8(2) (2017) 3315.

[149] M. Rezazadeh, J. Emami, F. Hasanzadeh, H. Sadeghi, M. Minaiyan, A. Mostafavi, M. Rostami, A. Lavasanifar, In vivo pharmacokinetics, biodistribution and anti-tumor effect of paclitaxel-loaded targeted chitosan-based polymeric micelle, Drug delivery 23(5) (2016) 1707-1717.

[150] R.m. Rosière, M. Van Woensel, M. Gelbcke, V.r. Mathieu, J. Hecq, T. Mathivet, M. Vermeersch, P. Van Antwerpen, K. Amighi, N. Wauthoz, New folate-grafted chitosan derivative to improve delivery of paclitaxel-loaded solid lipid nanoparticles for lung tumor therapy by inhalation, Molecular pharmaceutics 15(3) (2018) 899-910.

[151] S.K. Sahu, S. Maiti, T.K. Maiti, S.K. Ghosh, P. Pramanik, Hydrophobically modified carboxymethyl chitosan nanoparticles targeted delivery of paclitaxel, Journal of drug targeting 19(2) (2011) 104-113.

[152] D.R. Richardson, P. Ponka, The molecular mechanisms of the metabolism and transport of iron in normal and neoplastic cells, Biochimica Et Biophysica Acta (BBA)-Reviews on Biomembranes 1331(1) (1997) 1-40.

[153] H.A. Huebers, C.A. Finch, The physiology of transferrin and transferrin receptors, Physiological Reviews 67(2) (1987) 520-582.

[154] J.-P. Nam, S.-C. Park, T.-H. Kim, J.-Y. Jang, C. Choi, M.-K. Jang, J.-W. Nah, Encapsulation of paclitaxel into lauric acid-O-carboxymethyl chitosan-transferrin micelles for hydrophobic drug delivery and site-specific targeted delivery, International journal of pharmaceutics 457(1) (2013) 124135. 
[155] M. Nag, V. Gajbhiye, P. Kesharwani, N.K. Jain, Transferrin functionalized chitosan-PEG nanoparticles for targeted delivery of paclitaxel to cancer cells, Colloids and Surfaces B: Biointerfaces 148 (2016) 363-370.

[156] H. Koo, K.H. Min, S.C. Lee, J.H. Park, K. Park, S.Y. Jeong, K. Choi, I.C. Kwon, K. Kim, Enhanced drug-loading and therapeutic efficacy of hydrotropic oligomer-conjugated glycol chitosan nanoparticles for tumor-targeted paclitaxel delivery, Journal of controlled release 172(3) (2013) 823831.

[157] S.H. Yuk, K.S. Oh, S.H. Cho, S.Y. Kim, S. Oh, J.H. Lee, K. Kim, I.C. Kwon, Enhancement of the targeting capabilities of the paclitaxel-loaded pluronic nanoparticles with a glycol chitosan/heparin composite, Molecular pharmaceutics 9(2) (2011) 230-236.

[158] F. Zhang, J. Fei, M. Sun, Q. Ping, Heparin modification enhances the delivery and tumor targeting of paclitaxel-loaded N-octyl-N-trimethyl chitosan micelles, International journal of pharmaceutics 511(1) (2016) 390-402.

[159] J. Campos, M. Varas-Godoy, Z.S. Haidar, Physicochemical characterization of chitosanhyaluronan-coated solid lipid nanoparticles for the targeted delivery of paclitaxel: a proof-of-concept study in breast cancer cells, Nanomedicine 12(5) (2017) 473-490.

[160] P.-P. Lv, Y.-F. Ma, R. Yu, H. Yue, D.-Z. Ni, W. Wei, G.-H. Ma, Targeted delivery of insoluble cargo (paclitaxel) by PEGylated chitosan nanoparticles grafted with Arg-Gly-Asp (RGD), Molecular pharmaceutics 9(6) (2012) 1736-1747.

[161] W. Wang, D. Chen, K. Xi, Y. Chen, X. Zhang, Y. Wen, Z. Huang, X. Yu, G. Wang, R. Zhang, Impact of different types of lymphadenectomy combined with different extents of tumor resection on survival outcomes of stage I non-small cell lung cancer: a large cohort real-world study, Frontiers in Oncology 9 (2019) 642.

[162] J. Baselga, C.L. Arteaga, Critical update and emerging trends in epidermal growth factor receptor targeting in cancer, Journal of Clinical Oncology 23(11) (2005) 2445-2459.

[163] J. Cadranel, A.-M. Ruppert, M. Beau-Faller, M. Wislez, Therapeutic strategy for advanced EGFR mutant non-small-cell lung carcinoma, Critical reviews in oncology/hematology 88(3) (2013) 477-493.

[164] S. Maya, B. Sarmento, V.-K. Lakshmanan, D. Menon, V. Seabra, R. Jayakumar, Chitosan cross-linked docetaxel loaded EGF receptor targeted nanoparticles for lung cancer cells, International journal of biological macromolecules 69 (2014) 532-541. 
[165] I. Poudel, R. Ahiwale, A. Pawar, K. Mahadik, C. Bothiraja, Development of novel biotinylated chitosan-decorated docetaxel-loaded nanocochleates for breast cancer targeting, Artificial cells, nanomedicine, and biotechnology 46(sup2) (2018) 229-240.

[166] A. Pawar, C. Bothiraja, K. Shaikh, A. Mali, An insight into cochleates, a potential drug delivery system, RSC Advances 5(99) (2015) 81188-81202.

[167] M. Liu, X. Zhong, Z. Yang, Chitosan functionalized nanocochleates for enhanced oral absorption of cyclosporine A, Scientific reports 7 (2017) 41322.

[168] M. Asprea, I. Leto, M.C. Bergonzi, A.R. Bilia, Thyme essential oil loaded in nanocochleates: Encapsulation efficiency, in vitro release study and antioxidant activity, LWT 77 (2017) 497-502.

[169] W. Yang, Y. Cheng, T. Xu, X. Wang, L.-p. Wen, Targeting cancer cells with biotin-dendrimer conjugates, European journal of medicinal chemistry 44(2) (2009) 862-868.

[170] L. Zarif, Drug delivery by lipid cochleates, Methods in enzymology, Elsevier2005, pp. 314-329.

[171] A. Ghosh, W.D. Heston, Tumor target prostate specific membrane antigen (PSMA) and its regulation in prostate cancer, Journal of cellular biochemistry 91(3) (2004) 528-539.

[172] A.K. Pearce, J.D. Simpson, N.L. Fletcher, Z.H. Houston, A.V. Fuchs, P.J. Russell, A.K. Whittaker, K.J. Thurecht, Localised delivery of doxorubicin to prostate cancer cells through a PSMAtargeted hyperbranched polymer theranostic, Biomaterials 141 (2017) 330-339.

[173] R. Mo, X. Jin, N. Li, C. Ju, M. Sun, C. Zhang, Q. Ping, The mechanism of enhancement on oral absorption of paclitaxel by N-octyl-O-sulfate chitosan micelles, Biomaterials 32(20) (2011) 46094620 .

[174] H.-W. Yang, M.-Y. Hua, H.-L. Liu, R.-Y. Tsai, C.-K. Chuang, P.-C. Chu, P.-Y. Wu, Y.-H. Chang, H.-C. Chuang, K.-J. Yu, Cooperative dual-activity targeted nanomedicine for specific and effective prostate cancer therapy, ACS nano 6(2) (2012) 1795-1805.

[175] X. Feng, Y. Zhou, X. Xie, M. Li, H. Huang, L. Wang, X. Xu, J. Yu, Development of PSMAtargeted and core-crosslinked glycol chitosan micelles for docetaxel delivery in prostate cancer therapy, Materials Science and Engineering: C 96 (2019) 436-445.

[176] R. Augustine, P. Prasad, I.M.N. Khalaf, Therapeutic angiogenesis: From conventional approaches to recent nanotechnology-based interventions, Materials Science and Engineering: C (2019). 
[177] M. Zhi, K.-C. Wu, L. Dong, Z.-M. Hao, T.-Z. Deng, L. Hong, S.-H. Liang, P.-T. Zhao, T.-D. Qiao, Y. Wang, Characterization of a specific phage-displayed peptide binding to vasculature of human gastric cancer, Cancer biology \& therapy 3(12) (2004) 1232-1235.

[178] Z. Lei, N. Chai, M. Tian, Y. Zhang, G. Wang, J. Liu, Z. Tian, X. Yi, D. Chen, X. Li, Novel peptide GX1 inhibits angiogenesis by specifically binding to transglutaminase-2 in the tumorous endothelial cells of gastric cancer, Cell death \& disease 9(6) (2018) 579.

[179] X. Hui, Y. Han, S. Liang, Z. Liu, J. Liu, L. Hong, L. Zhao, L. He, S. Cao, B. Chen, Specific targeting of the vasculature of gastric cancer by a new tumor-homing peptide CGNSNPKSC, Journal of Controlled Release 131(2) (2008) 86-93.

[180] B. Chen, S. Cao, Y. Zhang, X. Wang, J. Liu, X. Hui, Y. Wan, W. Du, L. Wang, K. Wu, A novel peptide (GX1) homing to gastric cancer vasculature inhibits angiogenesis and cooperates with TNF alpha in antitumor therapy, BMC cell biology 10(1) (2009) 63.

[181] E. Zhang, R. Xing, S. Liu, K. Li, Y. Qin, H. Yu, P. Li, Vascular targeted chitosan-derived nanoparticles as docetaxel carriers for gastric cancer therapy, International journal of biological macromolecules 126 (2019) 662-672.

[182] H.-Y. Hwang, I.-S. Kim, I.C. Kwon, Y.-H. Kim, Tumor targetability and antitumor effect of docetaxel-loaded hydrophobically modified glycol chitosan nanoparticles, Journal of controlled release 128(1) (2008) 23-31.

[183] D. Torrecilla, M.V. Lozano, E. Lallana, J.I. Neissa, R. Novoa-Carballal, A. Vidal, E. Fernandez-Megia, D. Torres, R. Riguera, M.J. Alonso, Anti-tumor efficacy of chitosan-g-poly (ethylene glycol) nanocapsules containing docetaxel: anti-TMEFF-2 functionalized nanocapsules vs. non-functionalized nanocapsules, European Journal of Pharmaceutics and Biopharmaceutics 83(3) (2013) 330-337.

[184] B. Li, X.-X. Zhang, H.-Y. Huang, L.-Q. Chen, J.-H. Cui, Y. Liu, H. Jin, B.-J. Lee, Q.-R. Cao, Effective deactivation of A549 tumor cells in vitro and in vivo by RGD-decorated chitosanfunctionalized single-walled carbon nanotube loading docetaxel, International journal of pharmaceutics 543(1-2) (2018) 8-20.

[185] M. Mohajeri, B. Behnam, A. Sahebkar, Biomedical applications of carbon nanomaterials: Drug and gene delivery potentials, Journal of cellular physiology 234(1) (2019) 298-319.

[186] R. Mohammadinejad, A. Dadashzadeh, S. Moghassemi, M. Ashrafizadeh, A. Dehshahri, A. Pardakhty, H.A. Sassan, S.M. Sohrevardi, A. Mandegary, Shedding light on gene therapy: carbon dots for the minimally invasive image-guided delivery of plasmids and noncoding RNAs, Journal of advanced research (2019). 
[187] M. Karimi, N. Solati, A. Ghasemi, M.A. Estiar, M. Hashemkhani, P. Kiani, E. Mohamed, A. Saeidi, M. Taheri, P. Avci, Carbon nanotubes part II: a remarkable carrier for drug and gene delivery, Expert opinion on drug delivery 12(7) (2015) 1089-1105.

[188] L. Tao, J. Jiang, Y. Gao, C. Wu, Y. Liu, Biodegradable alginate-chitosan hollow nanospheres for codelivery of doxorubicin and paclitaxel for the effect of human lung cancer A549 cells, BioMed research international 2018 (2018).

[189] M. Rezaee, B. Behnam, M. Banach, A. Sahebkar, The Yin and Yang of carbon nanomaterials in atherosclerosis, Biotechnology advances (2018).

[190] M. Mohajeri, B. Behnam, G.E. Barreto, A. Sahebkar, Carbon nanomaterials and amyloid beta interactions: Possible potentials in the detection and treatment of Alzheimer's disease, Pharmacological research (2019).

[191] K.R. Karnati, Y. Wang, Understanding the co-loading and releasing of doxorubicin and paclitaxel using chitosan functionalized single-walled carbon nanotubes by molecular dynamics simulations, Physical Chemistry Chemical Physics 20(14) (2018) 9389-9400.

[192] C. Klumpp, K. Kostarelos, M. Prato, A. Bianco, Functionalized carbon nanotubes as emerging nanovectors for the delivery of therapeutics, Biochimica et Biophysica Acta (BBA)-Biomembranes 1758(3) (2006) 404-412.

[193] M. Ashrafizadeh, Z. Ahmadi, R. Mohammadinejad, N. Kaviyani, S. Tavakol, Monoterpenes modulating autophagy: A review study, Basic \& Clinical Pharmacology \& Toxicology.

[194] Z. Ahmadi, M. Ashrafizadeh, Melatonin as a potential modulator of Nrf2, Fundamental \& clinical pharmacology (2019).

[195] J. Wu, X. Bu, L. Dou, L. Fang, Q. Shen, Co-delivery of Docetaxel and Berbamine by Chitosan/Sulfobutylether- $\beta$-Cyclodextrin nanoparticles for enhancing bioavailability and anticancer activities, Journal of biomedical nanotechnology 11(10) (2015) 1847-1857.

[196] J. Emami, M. Rezazadeh, M. Rostami, F. Hassanzadeh, H. Sadeghi, A. Mostafavi, M. Minaiyan, A. Lavasanifar, Co-delivery of paclitaxel and $\alpha$-tocopherol succinate by novel chitosan-based polymeric micelles for improving micellar stability and efficacious combination therapy, Drug development and industrial pharmacy 41(7) (2015) 1137-1147.

[197] F. Xie, R.-L. Ding, W.-F. He, Z.-J.-L. Liu, S.-Z. Fu, J.-B. Wu, L.-L. Yang, S. Lin, Q.-L. Wen, In vivo antitumor effect of endostatin-loaded chitosan nanoparticles combined with paclitaxel on Lewis lung carcinoma, Drug delivery 24(1) (2017) 1410-1418. 
[198] X. Wang, Y. Chen, F.Z. Dahmani, L. Yin, J. Zhou, J. Yao, Amphiphilic carboxymethyl chitosan-quercetin conjugate with P-gp inhibitory properties for oral delivery of paclitaxel, Biomaterials 35(26) (2014) 7654-7665.

[199] S.D. Yang, W.J. Zhu, Q.L. Zhu, W.L. Chen, Z.X. Ren, F. Li, Z.Q. Yuan, J.Z. Li, Y. Liu, X.F. Zhou, Binary-copolymer system base on low-density lipoprotein-coupled N-succinyl chitosan lipoic acid micelles for co-delivery MDR1 siRNA and paclitaxel, enhances antitumor effects via reducing drug, Journal of Biomedical Materials Research Part B: Applied Biomaterials 105(5) (2017) 11141125 .

[200] S.A. Moosavian, A. Sahebkar, Aptamer-functionalized liposomes for targeted cancer therapy, Cancer letters 448 (2019) 144-154.

[201] R. Jafari, N.M. Zolbanin, J. Majidi, F. Atyabi, M. Yousefi, F. Jadidi-Niaragh, L. AghebatiMaleki, D. Shanehbandi, M.-S.S. Zangbar, H. Rafatpanah, Anti-Mucin1 Aptamer-Conjugated Chitosan Nanoparticles for Targeted Co-Delivery of Docetaxel and IGF-1R siRNA to SKBR3 Metastatic Breast Cancer Cells, Iranian biomedical journal 23(1) (2019) 21.

[202] C. Ferreira, C. Matthews, S. Missailidis, DNA aptamers that bind to MUC1 tumour marker: design and characterization of MUC1-binding single-stranded DNA aptamers, Tumor biology 27(6) (2006) 289301.

[203] W. Wei, P.-P. Lv, X.-M. Chen, Z.-G. Yue, Q. Fu, S.-Y. Liu, H. Yue, G.-H. Ma, Codelivery of mTERT siRNA and paclitaxel by chitosan-based nanoparticles promoted synergistic tumor suppression, Biomaterials 34(15) (2013) 3912-3923.

[204] R. Zhang, S.-B. Wang, A.-Z. Chen, W.-G. Chen, Y.-G. Liu, W.-G. Wu, Y.-Q. Kang, S.-F. Ye, Codelivery of paclitaxel and small interfering RNA by octadecyl quaternized carboxymethyl chitosanmodified cationic liposome for combined cancer therapy, Journal of biomaterials applications 30(3) (2015) 351360 .

[205] Y. Yang, Z. Wang, M. Li, S. Lu, Chitosan/pshRNA plasmid nanoparticles targeting MDR1 gene reverse paclitaxel resistance in ovarian cancer cells, Journal of Huazhong University of Science and Technology [Medical Sciences] 29(2) (2009) 239-242.

[206] N. Ashammakhi, S. Ahadian, M.A. Darabi, M. El Tahchi, J. Lee, K. Suthiwanich, A. Sheikhi, M.R. Dokmeci, R. Oklu, A. Khademhosseini, Minimally invasive and regenerative therapeutics, Advanced Materials 31(1) (2019) 1804041.

[207] S. Bano, M. Afzal, M.M. Waraich, K. Alamgir, S. Nazir, Paclitaxel loaded magnetic nanocomposites with folate modified chitosan/carboxymethyl surface; a vehicle for imaging and targeted drug delivery, International journal of pharmaceutics 513(1-2) (2016) 554-563. 
[208] W.-J. Xue, Y. Feng, F. Wang, Y.-B. Guo, P. Li, L. Wang, Y.-F. Liu, Z.-W. Wang, Y.-M. Yang, Q.-S. Mao, Asialoglycoprotein receptor-magnetic dual targeting nanoparticles for delivery of RASSF1A to hepatocellular carcinoma, Scientific Reports 6 (2016) 22149.

[209] P. Manivasagan, S. Bharathiraja, N.Q. Bui, I.G. Lim, J. Oh, Paclitaxel-loaded chitosan oligosaccharide-stabilized gold nanoparticles as novel agents for drug delivery and photoacoustic imaging of cancer cells, International journal of pharmaceutics 511(1) (2016) 367-379.

[210] H. Lian, T. Zhang, J. Sun, X. Liu, G. Ren, L. Kou, Y. Zhang, X. Han, W. Ding, X. Ai, Enhanced oral delivery of paclitaxel using acetylcysteine functionalized chitosan-vitamin E succinate nanomicelles based on a mucus bioadhesion and penetration mechanism, Molecular pharmaceutics 10(9) (2013) 3447-3458.

[211] H. Li, M. Huo, J. Zhou, Y. Dai, Y. Deng, X. Shi, J. Masoud, Enhanced oral absorption of paclitaxel in N-deoxycholic acid-N, O-hydroxyethyl chitosan micellar system, Journal of pharmaceutical sciences 99(11) (2010) 4543-4553.

[212] X. Wang, Y. Guo, L. Qiu, X. Wang, T. Li, L. Han, H. Ouyang, W. Xu, K. Chu, Preparation and evaluation of carboxymethyl chitosan-rhein polymeric micelles with synergistic antitumor effect for oral delivery of paclitaxel, Carbohydrate polymers 206 (2019) 121-131.

[213] G. Qu, S. Hou, D. Qu, C. Tian, J. Zhu, L. Xue, C. Ju, C. Zhang, Self-assembled micelles based on N-octyl-N'-phthalyl-O-phosphoryl chitosan derivative as an effective oral carrier of paclitaxel, Carbohydrate polymers 207 (2019) 428-439.

[214] D.S. Silva, A. Almeida, F. Prezotti, B. Cury, S.P. Campana-Filho, B. Sarmento, Synthesis and characterization of 3, 6-O, O'-dimyristoyl chitosan micelles for oral delivery of paclitaxel, Colloids and Surfaces B: Biointerfaces 152 (2017) 220-228.

[215] E. Lee, J. Lee, I.-H. Lee, M. Yu, H. Kim, S.Y. Chae, S. Jon, Conjugated chitosan as a novel platform for oral delivery of paclitaxel, Journal of medicinal chemistry 51(20) (2008) 6442-6449.

[216] N. Joshi, R. Saha, T. Shanmugam, B. Balakrishnan, P. More, R. Banerjee, Carboxymethylchitosan-tethered lipid vesicles: hybrid nanoblanket for oral delivery of paclitaxel, Biomacromolecules 14(7) (2013) 2272-2282.

[217] Y. Yu, M. Huo, Y. Fu, W. Xu, H. Cai, L. Yao, Q. Chen, Y. Mu, J. Zhou, T. Yin, NDeoxycholic acid-N, O-hydroxyethyl Chitosan with a Sulfhydryl Modification To Enhance the Oral Absorptive Efficiency of Paclitaxel, Molecular pharmaceutics 14(12) (2017) 4539-4550.

[218] R. He, C. Yin, Trimethyl chitosan based conjugates for oral and intravenous delivery of paclitaxel, Acta biomaterialia 53 (2017) 355-366. 
[219] P.-P. Lv, W. Wei, H. Yue, T.-Y. Yang, L.-Y. Wang, G.-H. Ma, Porous quaternized chitosan nanoparticles containing paclitaxel nanocrystals improved therapeutic efficacy in non-small-cell lung cancer after oral administration, Biomacromolecules 12(12) (2011) 4230-4239.

[220] G. Battogtokh, Y.T. Ko, Self-assembled chitosan-ceramide nanoparticle for enhanced oral delivery of paclitaxel, Pharmaceutical research 31(11) (2014) 3019-3030.

[221] M. Huo, Y. Fu, Y. Liu, Q. Chen, Y. Mu, J. Zhou, L. Li, W. Xu, T. Yin, N-mercapto acetyl-N'octyl-O, N "-glycol chitosan as an efficiency oral delivery system of paclitaxel, Carbohydrate polymers 181 (2018) 477-488.

[222] S. Saremi, R. Dinarvand, A. Kebriaeezadeh, S.N. Ostad, F. Atyabi, Enhanced oral delivery of docetaxel using thiolated chitosan nanoparticles: preparation, in vitro and in vivo studies, BioMed research international 2013 (2013).

[223] S. Saremi, F. Atyabi, S.P. Akhlaghi, S.N. Ostad, R. Dinarvand, Thiolated chitosan nanoparticles for enhancing oral absorption of docetaxel: preparation, in vitro and ex vivo evaluation, International journal of nanomedicine 6 (2011) 119.

[224] P.C. Christophersen, L. Zhang, A. Müllertz, H.M. Nielsen, M. Yang, H. Mu, Solid lipid particles for oral delivery of peptide and protein drugs II-the digestion of trilaurin protects desmopressin from proteolytic degradation, Pharmaceutical research 31(9) (2014) 2420-2428.

[225] W.M. Ibrahim, A.H. AlOmrani, A.E.B. Yassin, Novel sulpiride-loaded solid lipid nanoparticles with enhanced intestinal permeability, International journal of nanomedicine 9 (2014) 129.

[226] R. Rosenthal, D. Günzel, C. Finger, S.M. Krug, J.F. Richter, J.-D. Schulzke, M. Fromm, S. Amasheh, The effect of chitosan on transcellular and paracellular mechanisms in the intestinal epithelial barrier, Biomaterials 33(9) (2012) 2791-2800.

[227] T.-H. Yeh, L.-W. Hsu, M.T. Tseng, P.-L. Lee, K. Sonjae, Y.-C. Ho, H.-W. Sung, Mechanism and consequence of chitosan-mediated reversible epithelial tight junction opening, Biomaterials 32(26) (2011) 6164-6173.

[228] L.-L. Shi, J. Lu, Y. Cao, J.-Y. Liu, X.-X. Zhang, H. Zhang, J.-H. Cui, Q.-R. Cao, Gastrointestinal stability, physicochemical characterization and oral bioavailability of chitosan or its derivative-modified solid lipid nanoparticles loading docetaxel, Drug development and industrial pharmacy 43(5) (2017) 839-846.

[229] E. Lee, H. Kim, I.-H. Lee, S. Jon, In vivo antitumor effects of chitosan-conjugated docetaxel after oral administration, Journal of Controlled Release 140(2) (2009) 79-85. 
[230] J. Wu, Q. Shen, L. Fang, Sulfobutylether- $\beta$-cyclodextrin/chitosan nanoparticles enhance the oral permeability and bioavailability of docetaxel, Drug development and industrial pharmacy 39(7) (2013) 1010-1019.

[231] M.-X. Chen, B.-K. Li, D.-K. Yin, J. Liang, S.-S. Li, D.-Y. Peng, Layer-by-layer assembly of chitosan stabilized multilayered liposomes for paclitaxel delivery, Carbohydrate polymers 111 (2014) 298-304.

[232] W. Shi, C. Gu, H. Jiang, M. Zhang, M. Lang, Effects of amphiphilic chitosan-g-poly ( $\varepsilon-$ caprolactone) polymer additives on paclitaxel release from drug eluting implants, Materials Science and Engineering: C 45 (2014) 502-509.

[233] T. Wang, H. Zou, Y.-X. Liu, X.-W. Zhang, Effects of Paclitaxel-conjugated N-SuccinylHydroxyethyl Chitosan Film for Proliferative Cholangitis in Rabbit Biliary Stricture Model, Chinese medical journal 131(6) (2018) 696.

[234] J.I. Pesoa, M.J. Rico, V.R. Rozados, O.G. Scharovsky, J.A. Luna, L.N. Mengatto, Paclitaxel delivery system based on poly (lactide-co-glycolide) microparticles and chitosan thermo-sensitive gel for mammary adenocarcinoma treatment, Journal of Pharmacy and Pharmacology 70(11) (2018) 14941502.

[235] A. Jain, K. Thakur, G. Sharma, P. Kush, U.K. Jain, Fabrication, characterization and cytotoxicity studies of ionically cross-linked docetaxel loaded chitosan nanoparticles, Carbohydrate polymers 137 (2016) 65-74.

[236] N.S. Ravari, N. Goodarzi, F. Alvandifar, M. Amini, E. Souri, M.R. Khoshayand, Z.H. Mirzaie, F. Atyabi, R. Dinarvand, Fabrication and biological evaluation of chitosan coated hyaluronic acid-docetaxel conjugate nanoparticles in CD44+ cancer cells, DARU Journal of Pharmaceutical Sciences 24(1) (2016) 21.

[237] M.O. Alshraim, S. Sangi, G.I. Harisa, A.H. Alomrani, O. Yusuf, M.M. Badran, ChitosanCoated Flexible Liposomes Magnify the Anticancer Activity and Bioavailability of Docetaxel: Impact on Composition, Molecules 24(2) (2019) 250. 
2019-12-20

\section{Chitosan-based advanced materials for docetaxel and paclitaxel delivery: Recent advances and future directions in cancer theranostics}

Ashrafizadeh, Milad

Elsevier

Ashrafizadeh M, Ahmadi Z, Mohamadi N, et al., (2020) Chitosan-based advanced materials for docetaxel and paclitaxel delivery: Recent advances and future directions in cancer theranostics. International Journal of Biological Macromolecules, Volume 145, February 2020, pp. 282-300 https://doi.org/10.1016/j.jibiomac.2019.12.145 Downloaded from Cranfield Library Services E-Repository 